\title{
Article \\ Design and Experiment of Electronically Tunable Voltage-Mode Biquad and Output Current Amplitude Oscillator
}

\author{
San-Fu Wang ${ }^{1}$, Hua-Pin Chen ${ }^{2, *}$,, Yitsen $\mathrm{Ku}^{3}$ and Fang-Yu Liu ${ }^{2}$ \\ 1 Department of Electronic Engineering, National Chin-Yi University of Technology, Taiping, \\ Taichung 41170, Taiwan; sf_wang@ncut.edu.tw \\ 2 Department of Electronic Engineering, Ming Chi University of Technology, Taishan, \\ New Taipei 24301, Taiwan; M09158001@o365.mcut.edu.tw \\ 3 Department of Electrical Engineering, California State University Fullerton, Fullerton, CA 92831, USA; \\ joshuaku@fullerton.edu \\ * Correspondence: hpchen@mail.mcut.edu.tw; Tel.: +886-2-2908-9899; Fax: +886-2-2908-5247
}

check for

updates

Citation: Wang, S.-F.; Chen, H.-P.; Ku, Y.; Liu, F.-Y. Design and

Experiment of Electronically Tunable Voltage-Mode Biquad and Output Current Amplitude Oscillator. Appl. Sci. 2021, 11, 7357. https://doi.org/ 10.3390/app11167357

Academic Editors:

Wen-Hsiang Hsieh, Jia-Shing Sheu and Minvydas Ragulskis

Received: 12 July 2021

Accepted: 9 August 2021

Published: 10 August 2021

Publisher's Note: MDPI stays neutral with regard to jurisdictional claims in published maps and institutional affiliations.

Copyright: (c) 2021 by the authors. Licensee MDPI, Basel, Switzerland. This article is an open access article distributed under the terms and conditions of the Creative Commons Attribution (CC BY) license (https:// creativecommons.org/licenses/by/ $4.0 /)$

\begin{abstract}
This study presents an electronically tunable configuration for the design of a voltage-mode (VM) biquad with four input terminals and three output terminals. The proposed circuit employs four operational transconductance amplifiers (OTAs) and two grounded capacitors. Depending on the selections of the four input voltage signals, all the standard filtering functions can be realized. The proposed configuration simultaneously provides VM inverting band-pass, non-inverting low-pass, and non-inverting band-reject filtering functions without any component-matching choices. It offers the features of a resistorless structure, high-input impedance, electronic control of the pole frequency and quality factor, and low active and passive sensitivities. The measured power dissipation of the biquad is $0.96 \mathrm{~W}$ under $32 \mathrm{~mA}$ constant output current. The measured $1 \mathrm{~dB}$ power gain compression point of the output inverting band-pass filter is $-7 \mathrm{dBm}$. The measured value of the third-order intercept point is $5.136 \mathrm{dBm}$, and the measured value of the third-order intermodulation distortion is $-50.83 \mathrm{dBc}$. Moreover, the measured value of the spurious-free dynamic range is $53.49 \mathrm{~dB}$, and the figure-of-merit of the biquad is $268.75 \times 10^{3}$. In addition, an electronically controllable quadrature oscillator $(\mathrm{QO})$ with amplitude of output current can be realized using the proposed biquad. The proposed electronically controllable QO can provide an amplitude modulation signal or an amplitude shift keying signal, and is widely applied in signal processing systems and electronic communication systems. PSpice simulations and experimental results are accomplished.
\end{abstract}

Keywords: filters; oscillators; circuit design; modulation; voltage mode

\section{Introduction}

With increasing emphasis on voltage-mode (VM) biquads and oscillators, there is still a need to develop active components for VM biquads and oscillators. Oscillators [1-6] and biquads [7-14] are the most crucial circuit blocks in numerous applications, such as electronic communications, signal processing systems, and measurement systems. Especially in communication modulation systems, the sinusoidal oscillator is utilized to generate the carrier signals for amplitude modulation (AM) and amplitude shift keying (ASK) modulation. Most VM continuous-time biquad designs require the following features: (a) Achievement of five generic filtering signals, that is, low-pass filter (LPF), band-pass filter (BPF), highpass filter (HPF), band-reject filter (BRF), and all-pass filter (APF) responses. (b) Utilization of grounded capacitors, which is attractive for absorbing shunt parasitic capacitance of the active component and suitable for integrated circuit (IC) implementation. (c) High-input impedance, which is suitable for easy cascading in VM operation without needing any extra voltage followers. (d) Orthogonal tunability of resonance angular frequency $\left(\omega_{\mathrm{o}}\right)$ and quality factor $(Q)$. (e) Low $\omega_{\mathrm{O}}$ and $Q$ sensitivities with respect to the active and passive components. On the other hand, most quadrature oscillator $(\mathrm{QO})$ designs require the 
following features: realization of two quadrature sinusoidal voltage outputs with $90^{\circ}$ phase difference, independent control of frequency of oscillation (FO) and condition of oscillation (CO), electronic controllability, employment of grounded capacitors, and so on. However, the electronically controllable QO with amplitude of output current should also be considered. The amplitude of output current can be electronically adjusted by fine-tuning the direct-current $(\mathrm{DC})$ bias current $\left(\mathrm{I}_{\mathrm{B}}\right)$, which is suitable for signal processing systems and AM/ASK systems.

The VM electronically tunable, high-input impedance configurations used in the design of operational transconductance amplifier and capacitor (OTA-C) biquads are worthy of study, because they are suitable for the cascade in VM operation and the finetuning of the deviation of conventional electronic components. OTA provides highly linear electronic controllability and has a wide tunable range of transconductance gain $\left(g_{m}\right)$, which is an attractive feature for circuit designers [15-23]. OTAs are commercially available ICs, and LT1228 from Linear Technology Corporation [24] has been widely used to implement OTA-based circuits. The transconductance of LT1228 is electronically controlled by an external DC bias current $\mathrm{I}_{\mathrm{B}}$. The OTA-C biquad does not require a resistor, so it is very suitable for IC compared to other conventional active elements. Recently, some types of electronically tunable VM OTA-based biquads have been developed [25-30]. The circuits in $[25,26]$ employ six OTAs, but the proposed circuits cannot simultaneously realize LPF, inverting BPF (IBPF) and BRF responses from the same structure. In 2019, three interesting VM electronically tunable OTA-C biquads were proposed, which employ five OTAs along with two grounded capacitors [27-29]. The circuit proposed in [27] cannot use the same structure to realize LPF, IBPF, and BRF responses. The circuits proposed in $[28,29]$ can realize LPF, IBPF, and BRF responses with the same configuration, and can be simply converted to QO. However, none of the circuits proposed in [25-29] can be transformed into an electronically controllable $\mathrm{QO}$ with high-output impedance and amplitude-controllable sinusoidal current output signal. In 2020, another VM biquad using one dual-output OTA (DO-OTA), three OTAs, and two grounded capacitors was proposed [30]. The proposed circuit can realize LPF, IBPF, and BRF responses with the same configuration, and can be simply transferred to QO. However, the proposed circuit cannot electronically control the amplitude of the high-output impedance sinusoidal current signal. The amplitude of electronically controlled high-output impedance sinusoidal current signals can be applied in AM/ASK systems.

In this study, a new electronically tunable VM biquad with four inputs and three outputs is presented. The biquad has the following advantages: (i) using one DO-OTA, three OTAs, two grounded capacitors, and resistorless realization, which is suitable for integration, (ii) simultaneously realizing LPF, IBPF, and BRF responses without changing the circuit structure, (iii) realizing all the standard biquad functions from the same circuit structure, (iv) high-input impedance, (v) orthogonal electronic-tuning the characteristic parameters of $\omega_{\mathrm{o}}$ and $\mathrm{Q}$, (vi) easily transformed into a $\mathrm{QO}$ with high-output impedance and amplitude-controllable sinusoidal current output signal, and (vii) easily realizing AM/ASK of the oscillator. Table 1 summarizes the performance comparison between the proposed biquad and the previously reported biquads [25-30]. Regarding the OTA-based circuits proposed in [25-30], the proposed circuit has electronically controllable amplitude of sinusoidal current output with high-output impedance and can be used in an AM/ASK systems. Table 2 compares the additional performance of the proposed biquad and the previously reported biquads [25-30]. 
Table 1. Comparison of the proposed biquad and the biquads previously reported in the literature [25-30].

\begin{tabular}{|c|c|c|c|c|c|c|c|}
\hline Features & [25] & [26] & [27] & [28] & [29] & [30] & Proposed \\
\hline $\begin{array}{l}\text { Active and passive } \\
\text { elements }\end{array}$ & $\begin{array}{l}6 \text { OTAs, } \\
\text { and } 2 \mathrm{C}\end{array}$ & $\begin{array}{c}6 \text { OTAs, } 2 \\
\text { Rmos, and } 2 \text { C }\end{array}$ & $\begin{array}{l}5 \text { OTAs, } \\
\text { and } 2 \mathrm{C}\end{array}$ & $\begin{array}{l}5 \text { OTAs, } \\
\text { and } 2 \mathrm{C}\end{array}$ & $\begin{array}{l}5 \text { OTAs, } \\
\text { and } 2 \mathrm{C}\end{array}$ & $\begin{array}{l}1 \text { DO-OTA, } 3 \\
\text { OTAs, and } 2 \text { C }\end{array}$ & $\begin{array}{l}1 \text { DO-OTA, } 3 \\
\text { OTAs, and } 2 \text { C }\end{array}$ \\
\hline Resistorless structure & yes & no & yes & yes & yes & yes & yes \\
\hline $\begin{array}{l}\text { Component-matching } \\
\text { condition }\left(R=1 / g_{m}\right)\end{array}$ & no & yes & no & no & no & no & no \\
\hline $\begin{array}{l}\text { Using grounded passive } \\
\text { elements }\end{array}$ & yes & yes & yes & yes & yes & yes & yes \\
\hline $\begin{array}{c}\text { No inverting-type input } \\
\text { signal }\end{array}$ & yes & yes & yes & yes & yes & yes & yes \\
\hline High-input impedances & yes & yes & yes & yes & yes & yes & yes \\
\hline $\begin{array}{c}\text { Orthogonal control of } \omega_{\mathrm{O}} \\
\text { and } Q\end{array}$ & yes & yes & yes & yes & yes & yes & yes \\
\hline $\begin{array}{l}\text { Versatile input/output } \\
\text { functions }\end{array}$ & no & no & no & yes & yes & yes & yes \\
\hline $\begin{array}{l}\text { Simultaneously realizing } \\
\text { three filtering functions }\end{array}$ & no & no & no & yes & yes & yes & yes \\
\hline $\begin{array}{l}\text { Offering five standard } \\
\text { filters }\end{array}$ & yes & yes & yes & yes & yes & yes & yes \\
\hline Easily transformed into a & & & & & & & \\
\hline $\begin{array}{l}\text { QO with output current } \\
\text { amplitude }\end{array}$ & no & no & no & no & no & no & yes \\
\hline $\begin{array}{l}\text { Easily realizing oscillator } \\
\text { with AM/ASK signals }\end{array}$ & no & no & no & no & no & no & yes \\
\hline
\end{tabular}

Note: QO: quadrature oscillator; AM: amplitude modulation; ASK: amplitude shift keying.

Table 2. Characteristic comparisons of the proposed biquad with the biquads previously reported in the literature [25-30].

\begin{tabular}{|c|c|c|c|c|c|c|c|}
\hline Features & [25] & [26] & [27] & [28] & [29] & [30] & Proposed \\
\hline Power supply & $\pm 15 \mathrm{~V}$ & $\pm 5 \mathrm{~V}$ & $\pm 15 \mathrm{~V}$ & $\pm 15 \mathrm{~V}$ & $\pm 15 \mathrm{~V}$ & $\pm 15 \mathrm{~V}$ & $\pm 15 \mathrm{~V}$ \\
\hline $\begin{array}{c}\text { Verification of } \\
\text { simulation/measurement }\end{array}$ & yes/yes & yes/yes & yes/yes & yes/yes & yes/yes & yes/yes & yes/yes \\
\hline $\begin{array}{l}\text { Simulated the power } \\
\text { dissipation }(\mathrm{W})\end{array}$ & none & none & none & none & 0.86 & 0.92 & 0.92 \\
\hline $\begin{array}{l}\text { Measured the power } \\
\text { dissipation }(\mathrm{W})\end{array}$ & none & none & none & 0.86 & 1.2 & 1.23 & 0.96 \\
\hline Central frequency of the filter $(\mathrm{kHz})$ & 10 & 32.9 & 238.7 & 159.15 & 217 & 144.7 & 144.7 \\
\hline Maximum output noise $(\mathrm{nV} / \sqrt{\mathrm{Hz}})$ & none & none & none & none & none & none & 7.937 \\
\hline $\begin{array}{l}\text { Measured the output P1dB } \\
\text { point }(\mathrm{dBm})\end{array}$ & none & none & none & -9.2 & none & -5.9 & -7 \\
\hline Measured the TOI point $(\mathrm{dBm})$ & none & none & none & -5.66 & none & -2.597 & 5.136 \\
\hline Measured the IMD3 (dBc) & none & none & $\begin{array}{l}-30.03(@) \\
80 \mathrm{mVpp})\end{array}$ & $\begin{array}{l}-42.35(@) \\
60 \mathrm{mVpp})\end{array}$ & $\begin{array}{l}-31.16(@) \\
90 \mathrm{mVpp})\end{array}$ & $\begin{array}{l}-48.67(@) \\
63 \mathrm{mVpp})\end{array}$ & $\begin{array}{l}-50.83 \text { (@) } \\
126 \mathrm{mVpp})\end{array}$ \\
\hline $\operatorname{FoM}\left(\times 10^{3}\right)$ & none & none & none & none & none & none & 268.75 \\
\hline
\end{tabular}

Note: P1dB: 1 dB power gain compression; TOI: third-order intercept; IMD3: third-order intermodulation distortion; FoM: figure-of-merit.

\section{Proposed Electronically Tunable VM OTA-C Biquad}

OTA offers a high linear electronic controllability and its transconductance gain has a wide tunable range [19]. The electrical symbol of the OTA is shown in Figure 1. According to Figure 1, the single-ended output OTA consists of an input differential pair, an output current mirror, and a $g_{m}$ control unit. The output current of a single-ended OTA is characterized by $\mathrm{I}_{\mathrm{O}}=\mathrm{g}_{\mathrm{m}}(\mathrm{V}+-\mathrm{V}-)$, where $\mathrm{V}+$ and $\mathrm{V}-$ are the input signals applied to the non-inverting and inverting terminals, respectively [19]. The $g_{m}$ value is electrically controllable by an external DC bias current $\mathrm{I}_{\mathrm{B}}$, which leads electronic controllability to the design biquad or oscillator parameters. The DO-OTA has two identical current outputs, which can be described by $\mathrm{I}_{\mathrm{O}}=\mathrm{I}_{\mathrm{Q}}=\mathrm{g}_{\mathrm{m}}(\mathrm{V}+-\mathrm{V}-)$. Figure 2 shows the proposed biquad 
with four inputs and three outputs. It is configured by only one DO-OTA, three OTAs, and two grounded capacitors. Routine analysis of the proposed electronically controllable OTA-C biquad in Figure 2 yielded the following three-output voltage signals.

$$
\begin{aligned}
& \mathrm{V}_{\mathrm{o} 1}=\frac{1}{\mathrm{D}(\mathrm{s})}\left[\mathrm{g}_{\mathrm{m} 1} \mathrm{~g}_{\mathrm{m} 2} \mathrm{~g}_{\mathrm{m} 3} \mathrm{~V}_{\mathrm{i} 1}+\mathrm{g}_{\mathrm{m} 1} \mathrm{~g}_{\mathrm{m} 3} \mathrm{~g}_{\mathrm{m} 4}\left(\mathrm{~V}_{\mathrm{i} 2}-\mathrm{V}_{\mathrm{i} 4}\right)+\mathrm{sC}_{2} \mathrm{~g}_{\mathrm{m} 1} \mathrm{~g}_{\mathrm{m} 3} \mathrm{~V}_{\mathrm{i} 3}\right] \\
& \mathrm{V}_{\mathrm{o} 2}=\frac{1}{\mathrm{D}(\mathrm{s})}\left[-\mathrm{sC}_{1} \mathrm{~g}_{\mathrm{m} 1} \mathrm{~g}_{\mathrm{m} 2} \mathrm{~V}_{\mathrm{i} 1}-\mathrm{sC}_{1} \mathrm{~g}_{\mathrm{m} 1} \mathrm{~g}_{\mathrm{m} 4}\left(\mathrm{~V}_{\mathrm{i} 2}-\mathrm{V}_{\mathrm{i} 4}\right)\right. \\
& \left.+\left(\mathrm{sC}_{1} \mathrm{~g}_{\mathrm{m} 2} \mathrm{~g}_{\mathrm{m} 3}+\mathrm{g}_{\mathrm{m} 1} \mathrm{~g}_{\mathrm{m} 2} \mathrm{~g}_{\mathrm{m} 3}\right) \mathrm{V}_{\mathrm{i} 3}\right] \\
& \mathrm{V}_{\mathrm{o} 3}=\frac{1}{\mathrm{D}(\mathrm{s})}\left[\left(\mathrm{s}^{2} \mathrm{C}_{1} \mathrm{C}_{2} \mathrm{~g}_{\mathrm{m} 1}+\mathrm{g}_{\mathrm{m} 1} \mathrm{~g}_{\mathrm{m} 2} \mathrm{~g}_{\mathrm{m} 3}\right) \mathrm{V}_{\mathrm{i} 1}-\mathrm{sC}_{1} \mathrm{~g}_{\mathrm{m} 3} \mathrm{~g}_{\mathrm{m} 4}\left(\mathrm{~V}_{\mathrm{i} 2}-\mathrm{V}_{\mathrm{i} 4}\right)\right. \\
& \left.-\mathrm{s}^{2} \mathrm{C}_{1} \mathrm{C}_{2} \mathrm{~g}_{\mathrm{m} 3} \mathrm{~V}_{\mathrm{i} 3}\right]
\end{aligned}
$$

where the denominator $\mathrm{D}(\mathrm{s})$ is:

$$
\mathrm{D}(\mathrm{s})=\mathrm{s}^{2} \mathrm{C}_{1} \mathrm{C}_{2} \mathrm{~g}_{\mathrm{m} 1}+\mathrm{sC}_{1} \mathrm{~g}_{\mathrm{m} 2} \mathrm{~g}_{\mathrm{m} 3}+\mathrm{g}_{\mathrm{m} 1} \mathrm{~g}_{\mathrm{m} 2} \mathrm{~g}_{\mathrm{m} 3}
$$

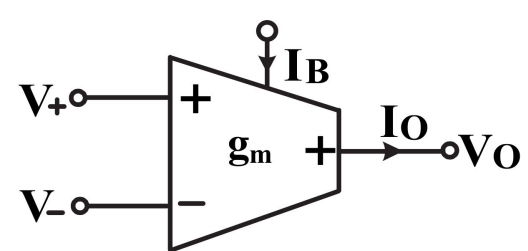

(a)

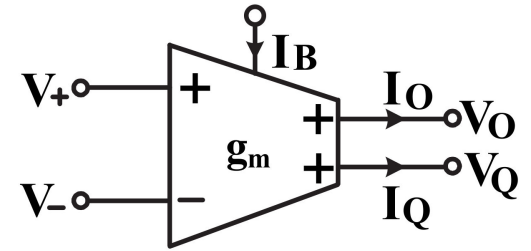

(b)

Figure 1. Symbol of the OTA. (a) Single-ended output OTA and (b) DO-OTA.

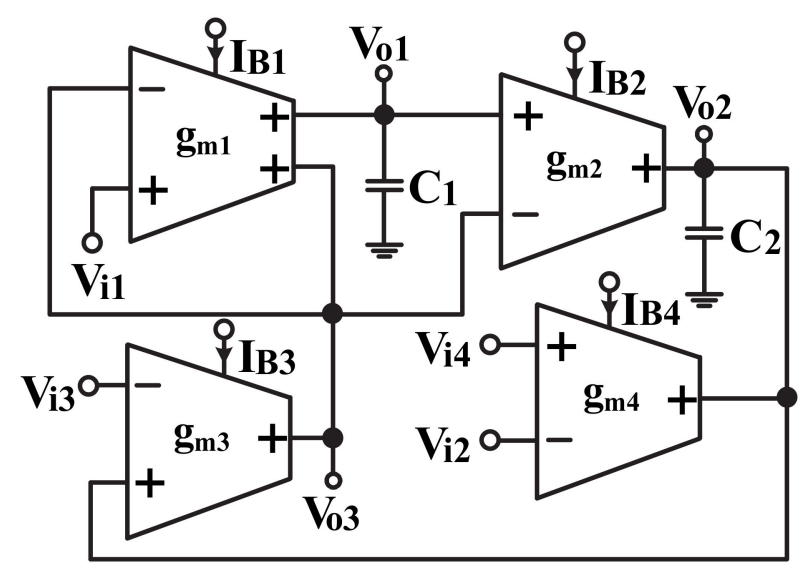

Figure 2. Proposed VM OTA-C biquad.

From Equations (1)-(4), the VM transfer functions can be obtained according to input and output conditions as follows:

Part I: If only $V_{i 1}$ is applied to the input voltage signal, $V_{\text {in }}$, the output voltage functions $V_{\mathrm{o} 1}, V_{\mathrm{o} 2}$, and $V_{\mathrm{o} 3}$ can be simultaneously obtained, as shown in Equations (5)-(7):

$$
\begin{gathered}
\frac{V_{\mathrm{o} 1}}{V_{\text {in }}}=\frac{g_{\mathrm{m} 1} g_{\mathrm{m} 2} g_{\mathrm{m} 3}}{D(s)} \\
\frac{V_{\mathrm{o} 2}}{V_{\text {in }}}=\frac{-\mathrm{sC}_{1} g_{\mathrm{m} 1} g_{\mathrm{m} 2}}{\mathrm{D}(\mathrm{s})} \\
\frac{\mathrm{V}_{\mathrm{o} 3}}{V_{\text {in }}}=\frac{\mathrm{s}^{2} \mathrm{C}_{1} \mathrm{C}_{2} \mathrm{~g}_{\mathrm{m} 1}+\mathrm{g}_{\mathrm{m} 1 \mathrm{~g}_{\mathrm{m} 2} \mathrm{~g}_{\mathrm{m} 3}}}{\mathrm{D}(\mathrm{s})}
\end{gathered}
$$


Equations (5)-(7) show that the LPF, IBPF, and BRF signals can be simultaneously implemented.

Part II: According to Equation (3), the proposed biquad can realize six different generic filtering signals. Assuming that $\mathrm{g}_{\mathrm{m} 1}=\mathrm{g}_{\mathrm{m} 3}$ and $\mathrm{g}_{\mathrm{m} 2}=\mathrm{g}_{\mathrm{m} 4}=\mathrm{kg}_{\mathrm{m} 3}$, where $\mathrm{k}$ is the scale factor, Equation (3) can be rewritten as:

$$
V_{03}=\frac{\left(s^{2}+\frac{1}{\tau_{1} \tau_{2}}\right) V_{i 1}-s \frac{k}{\tau_{2}}\left(V_{i 2}-V_{i 4}\right)-s^{2} V_{i 3}}{s^{2}+s \frac{k}{\tau_{2}}+\frac{1}{\tau_{1} \tau_{2}}}
$$

where in Equation (8), $\tau_{1}=\left(\mathrm{C}_{1} / \mathrm{g}_{\mathrm{m} 2}\right)$ and $\tau_{2}=\left(\mathrm{C}_{2} / \mathrm{g}_{\mathrm{m} 3}\right)$ are the realized time-constants. Examining Equation (8) shows that the LPF, BPF, IBPF, inverting HPF (IHPF), BRF, and APF signals can be implemented by appropriately applying the input signals without the need for an inverting-type input signal. According to Equation (8), the following six different generic filtering signals can be obtained as:

(1) LPF: $V_{\mathrm{i} 2}=V_{\mathrm{i} 4}=0$ and $\mathrm{V}_{\mathrm{i} 1}=\mathrm{V}_{\mathrm{i} 3}=\mathrm{V}_{\mathrm{in}}$.

(2) BPF: $V_{\mathrm{i} 1}=\mathrm{V}_{\mathrm{i} 2}=\mathrm{V}_{\mathrm{i} 3}=0$ and $\mathrm{V}_{\mathrm{i} 4}=\mathrm{V}_{\mathrm{in}}$.

(3) IBPF: $V_{\mathrm{i} 1}=V_{\mathrm{i} 3}=V_{\mathrm{i} 4}=0$ and $V_{\mathrm{i} 2}=V_{\mathrm{in}}$.

(4) IHPF: $V_{\mathrm{i} 1}=\mathrm{V}_{\mathrm{i} 2}=\mathrm{V}_{\mathrm{i} 4}=0$ and $\mathrm{V}_{\mathrm{i} 3}=\mathrm{V}_{\mathrm{in}}$.

(5) BRF: $V_{\mathrm{i} 2}=V_{\mathrm{i} 3}=V_{\mathrm{i} 4}=0$ and $\mathrm{V}_{\mathrm{i} 1}=\mathrm{V}_{\mathrm{in}}$.

(6) APF: $\mathrm{V}_{\mathrm{i} 3}=\mathrm{V}_{\mathrm{i} 4}=0$ and $\mathrm{V}_{\mathrm{i} 1}=\mathrm{V}_{\mathrm{i} 2}=\mathrm{V}_{\mathrm{in}}$.

From Parts I and II, the biquad structure can be applied as a single-input and threeoutput VM multifunction biquad, and the LPF, IBPF, and BRF functions from the three output terminals can be realized without any component-matching conditions. It can also be applied as a four-input and single-output VM universal biquad, and can realize six different generic filtering signals in the same structure. The characteristic parameters $\omega_{0}$ and $\mathrm{Q}$ of the biquad can be calculated as:

$$
\omega_{\mathrm{o}}=\sqrt{\frac{\mathrm{g}_{\mathrm{m} 2} \mathrm{~g}_{\mathrm{m} 3}}{\mathrm{C}_{1} \mathrm{C}_{2}}}, \mathrm{Q}=\mathrm{g}_{\mathrm{m} 1} \sqrt{\frac{\mathrm{C}_{2}}{\mathrm{C}_{1} \mathrm{~g}_{\mathrm{m} 2} \mathrm{~g}_{\mathrm{m} 3}}}
$$

\section{Proposed Electronically Tunable VM QO with Amplitude of Output Current}

The biquad in Figure 2 can be used as the proposed $Q O$ with output current amplitude, when $V_{i 1}$ and $V_{i 2}$ are connected to the ground while $V_{i 3}$ and $V_{i 4}$ are connected to $V_{01}$ and $\mathrm{V}_{\mathrm{o} 2}$, respectively. The current output terminal of $\mathrm{g}_{\mathrm{m} 4}$ in Figure 2 can be the AM/ASK modulated current output terminal, as shown in Figure 3. The characteristic equation of the electronically controllable OTA-C QO with amplitude of output current can be obtained as in Equation (10).

$$
\mathrm{s}^{2} \mathrm{C}_{1} \mathrm{C}_{2} \mathrm{~g}_{\mathrm{m} 1}+\mathrm{s}\left(\mathrm{C}_{1} \mathrm{~g}_{\mathrm{m} 2}-\mathrm{C}_{2} \mathrm{~g}_{\mathrm{m} 1}\right) \mathrm{g}_{\mathrm{m} 3}+\mathrm{g}_{\mathrm{m} 1} \mathrm{~g}_{\mathrm{m} 2} \mathrm{~g}_{\mathrm{m} 3}=0
$$

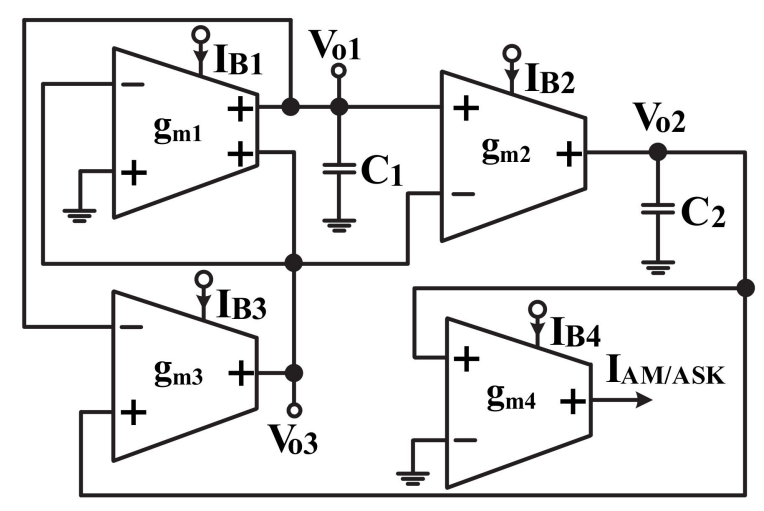

Figure 3. Proposed VM OTA-C QO with amplitude of output current. 
Thus, $\mathrm{CO}$ and FO of the electronically controllable OTA-C QO are as follows:

$$
\begin{gathered}
C O: C_{1} g_{m 2} \leq C_{2} g_{m 1} \\
\text { FO : } f_{o}=\frac{1}{2 \pi} \sqrt{\frac{g_{m 2} g_{m 3}}{C_{1} C_{2}}}
\end{gathered}
$$

From Equations (11) and (12), CO can be controlled independently from FO by varying $\mathrm{g}_{\mathrm{m} 1}$, and FO can be controlled by $\mathrm{g}_{\mathrm{m} 3}$. Hence, the proposed QO in Figure 3 has independent electronic control of $\mathrm{CO}$ and $\mathrm{FO}$. The two output voltages, $\mathrm{V}_{\mathrm{o} 1}$ and $\mathrm{V}_{\mathrm{o} 3}$, of the proposed QO can be expressed as:

$$
\frac{\mathrm{V}_{\mathrm{o} 1}}{\mathrm{~V}_{\mathrm{o} 3}}=-\frac{\mathrm{g}_{\mathrm{m} 1}}{\mathrm{sC}_{1}}
$$

For sinusoidal steady state, Equation (13) becomes:

$$
\frac{V_{\mathrm{o} 1}}{V_{\mathrm{o} 3}}=\frac{\mathrm{g}_{\mathrm{m} 1}}{\omega_{\mathrm{o}} \mathrm{C}_{1}} \mathrm{e}^{\mathrm{j} 90^{\circ}}
$$

Based on Equation (14), the proposed QO has two sinusoidal signal voltages with $90^{\circ}$ phase difference. Furthermore, the output current $\mathrm{I}_{\mathrm{AM} / \mathrm{ASK}}$ can be obtained as:

$$
\mathrm{I}_{\mathrm{AM} / \mathrm{ASK}}=\mathrm{g}_{\mathrm{m} 4} \mathrm{~V}_{\mathrm{o} 2}
$$

The amplitude of the sinusoidal signal $\mathrm{I}_{\mathrm{AM} / \mathrm{ASK}}$ can be independently controlled by the OTA's $g_{\mathrm{m} 4}$ transconductance gain. The value of $\mathrm{g}_{\mathrm{m} 4}$ can be varied through its $\mathrm{I}_{\mathrm{B} 4}$. This means that the value of $\mathrm{g}_{\mathrm{m} 4}$ can be tuned by $\mathrm{I}_{\mathrm{B} 4}$ without affecting $\mathrm{CO}$ and $\mathrm{FO}$. Therefore, if a modulation signal is applied to $\mathrm{I}_{\mathrm{B} 4}$, the AM/ASK signals can be realized from $\mathrm{I}_{\mathrm{AM}}$ /ASK. In addition, the output current $\mathrm{I}_{\mathrm{AM}} / \mathrm{ASK}$ port has high impedance. The load can be easily driven without using a buffering device.

\section{Effect of Non-Idealities Analysis}

In this section, the non-ideal circuit model of OTA will be considered. The nonideal terminal effects of OTA are considered, including non-ideal current transfer error parameters and non-ideal finite input and output parasitic elements. Figure 4 illustrates a non-ideal OTA model with various parasitic elements [19], where $R_{P j}, R_{n j}, R_{o j}, R_{q j}$, $C_{P j}, C_{n j}, C_{o j}$, and $C_{q j}$ represent the finite parasitic resistances and capacitances of the input and output terminals of the jth OTA, respectively. In Figure 4, the non-ideal dualoutput currents of OTA are given as $\mathrm{I}_{\mathrm{O}}=\gamma \mathrm{g}_{\mathrm{m}}(\mathrm{V}+-\mathrm{V}-)$ and $\mathrm{I}_{\mathrm{Q}}=\eta \mathrm{g}_{\mathrm{m}}(\mathrm{V}+-\mathrm{V}-)$, where $\gamma=1-\varepsilon_{\gamma \mathrm{i}}$ and $\eta=1-\varepsilon_{\eta \mathrm{i}}$. Here, $\varepsilon_{\gamma \mathrm{i}}\left(\left|\varepsilon_{\gamma \mathrm{i}}\right| \ll 1\right)$ and $\varepsilon_{\eta \mathrm{i}}\left(\left|\varepsilon_{\eta \mathrm{i}}\right| \ll 1\right)$ indicate the non-ideal dual-output currents of OTA current tracking errors. Taking the non-ideal OTA model into account, the biquad shown in Figure 2 can be modified to become the biquad presented in Figure 5. The effect of the non-ideal current transfer error parameters and the parasitic impedance elements on the characteristic parameters of $\omega_{0}$ and $Q$ has been investigated to indicate the performance of the proposed biquad. Accounting for the parasitic elements in Figure 5, the non-ideal characteristic equation, $\mathrm{D}_{1}(\mathrm{~s})$, of the equivalent circuit model in Figure 5 becomes:

$$
\begin{aligned}
\mathrm{D}_{1}(\mathrm{~s})= & \beta_{1} \mathrm{~s}^{2} \mathrm{C}_{1}^{\prime} \mathrm{C}_{2}^{\prime} \mathrm{g}_{\mathrm{m} 1}\left(1+\frac{\mathrm{P}}{\beta_{1} \mathrm{C}_{1}^{\prime} \mathrm{C}_{2}^{\prime} \mathrm{g}_{\mathrm{m} 1}}\right)+\alpha_{2} \alpha_{3} \mathrm{~s}_{1}^{\prime} \mathrm{g}_{\mathrm{m} 2} \mathrm{~g}_{\mathrm{m} 3}\left(1+\frac{\mathrm{R}}{\alpha_{2} \alpha_{3} \mathrm{C}_{1}^{\prime} \mathrm{g}_{\mathrm{m} 2} \mathrm{~g}_{\mathrm{m} 3}}\right) \\
& +\alpha_{1} \alpha_{2} \alpha_{3} \mathrm{~g}_{\mathrm{m} 1} \mathrm{~g}_{\mathrm{m} 2} \mathrm{~g}_{\mathrm{m} 3}\left(1+\frac{\alpha_{1} \alpha_{2} \alpha_{3} \mathrm{~g}_{\mathrm{m} 1} \mathrm{~g}_{\mathrm{m} 2} \mathrm{~g}_{\mathrm{m} 3}}{\alpha}\right)
\end{aligned}
$$

where $P=C_{1}^{\prime} C_{2}^{\prime} G_{3 p}+C_{1}^{\prime} C_{3 p} G_{2 p}+C_{2}^{\prime} C_{3 p} G_{1 p}, Q=C_{1}^{\prime} G_{2 p} G_{3 p}+\beta_{1} C_{1}^{\prime} G_{2 p} g_{m 1}+C_{2}^{\prime} G_{1 p} G_{3 p}+$ $\beta_{1} C_{2}^{\prime} G_{1 p} g_{m 1}+C_{3 p} G_{1 p} G_{2 p}+s^{2} C_{1}^{\prime} C_{2}^{\prime} C_{3 p}, R=G_{1 p} G_{2 p} G_{3 p}+\beta_{1} G_{1 p} G_{2 p} g_{m 1}+\alpha_{2} \alpha_{3} g_{m 2} g_{m 3} G_{1 p}$, $\mathrm{C}_{1}^{\prime}=\mathrm{C}_{1}+\mathrm{C}_{1 \mathrm{p}}, \mathrm{C}_{2}^{\prime}=\mathrm{C}_{2}+\mathrm{C}_{2 \mathrm{p}}, \mathrm{C}_{1 \mathrm{p}}=\mathrm{C}_{\mathrm{o} 1}+\mathrm{C}_{\mathrm{p} 2}, \mathrm{C}_{2 \mathrm{p}}=\mathrm{C}_{\mathrm{o} 2}+\mathrm{C}_{\mathrm{o} 4}+\mathrm{C}_{\mathrm{p} 3}, \mathrm{C}_{3 \mathrm{p}}=\mathrm{C}_{\mathrm{q} 1}+\mathrm{C}_{\mathrm{o} 3}+$ $C_{n 1}+C_{n 2}, G_{1 p}=\frac{1}{R_{1 p}}, G_{2 p}=\frac{1}{R_{2 p}}, G_{3 p}=\frac{1}{R_{3 p}}, R_{1 p}=R_{o 1} / / R_{p 2}, R_{2 p}=R_{02} / / R_{04} / / R_{p 3}$, and $\mathrm{R}_{3 \mathrm{p}}=\mathrm{R}_{\mathrm{q} 1} / / \mathrm{R}_{\mathrm{o} 3} / / \mathrm{R}_{\mathrm{n} 1} / / \mathrm{R}_{\mathrm{n} 2}$. 


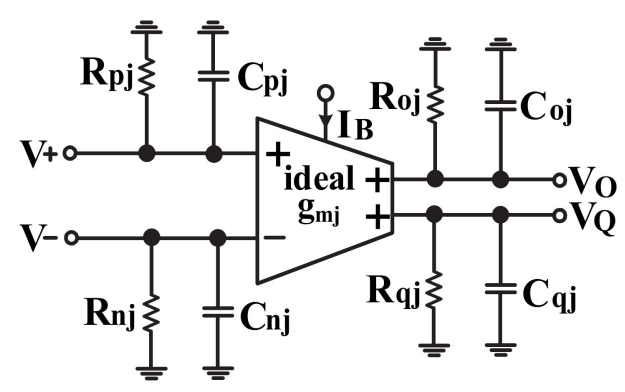

Figure 4. The non-ideal OTA with its parasitic resistors and capacitors.

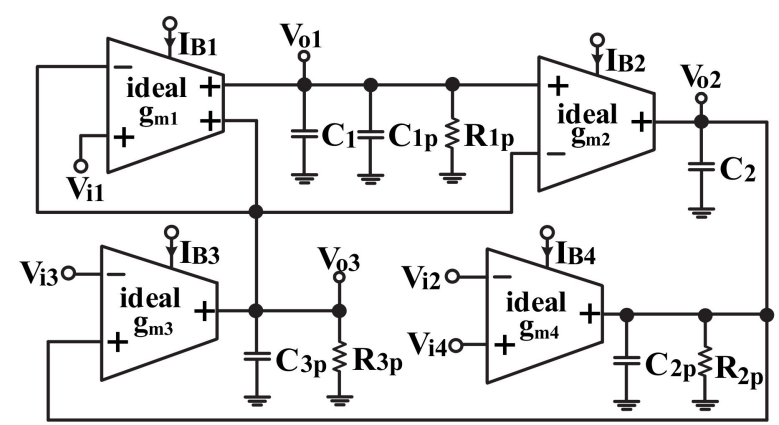

Figure 5. The influence of parasitic components on the proposed VM biquad.

According to Equation (16), non-ideal parasitic elements and non-ideal current transfer error parameters influence $\omega_{\mathrm{o}}$ and Q. Neglecting the third-order effects, the biquad can operate as an ideal case by satisfying the following conditions:

$$
\begin{gathered}
\frac{1}{\mathrm{sC}_{1}^{\prime}}<<\mathrm{R}_{1 \mathrm{p}} \\
\frac{1}{\mathrm{sC}_{2}^{\prime}}<<\mathrm{R}_{2 \mathrm{p}} \\
\mathrm{sC}_{3 \mathrm{p}}+\mathrm{G}_{3 \mathrm{p}}<<\mathrm{g}_{\mathrm{m} 1}
\end{gathered}
$$

Hence, $\mathrm{D}_{1}(\mathrm{~s})$ of Figure 5 can be approximated as:

$$
\mathrm{D}_{2}(\mathrm{~s})=\beta_{1} \mathrm{~s}^{2} \mathrm{C}_{1}^{\prime} \mathrm{C}_{2}^{\prime} \mathrm{g}_{\mathrm{m} 1}+\alpha_{2} \alpha_{3} \mathrm{sC}_{1}^{\prime} \mathrm{g}_{\mathrm{m} 2} \mathrm{~g}_{\mathrm{m} 3}+\alpha_{1} \alpha_{2} \alpha_{3} \mathrm{~g}_{\mathrm{m} 1} \mathrm{~g}_{\mathrm{m} 2} \mathrm{~g}_{\mathrm{m} 3}
$$

In this case, $\omega_{\mathrm{o}}$ and $\mathrm{Q}$ were modified as:

$$
\begin{gathered}
\omega_{\mathrm{o}}=\sqrt{\frac{\alpha_{1} \alpha_{2} \alpha_{3} g_{\mathrm{m} 2} g_{\mathrm{m} 3}}{\beta_{1} C_{1}^{\prime} C_{2}^{\prime}}} \\
Q=g_{\mathrm{m} 1} \sqrt{\frac{\alpha_{1} C_{2}^{\prime}}{\beta_{1} \alpha_{2} \alpha_{3} C_{1}^{\prime} g_{\mathrm{m} 2} g_{\mathrm{m} 3}}}
\end{gathered}
$$

The sensitivities of the parameters $\omega_{0}$ and $Q$ in Equations (21) and (22) were not larger than unity in magnitude. Therefore, the proposed biquad can be classified as an insensitive circuit.

\section{Simulation and Experimental Results}

To demonstrate the feasibility of the proposed OTA-C configurations, the proposed biquad and QO were simulated in PSpice using the macro-model of LT1228 IC and were measured in the laboratory using commercially available IC from Linear Technology Inc., LT1228. The power supply was $\pm 15 \mathrm{~V}$. The transconductance gain is given by 
$\mathrm{g}_{\mathrm{m}}=10 \mathrm{I}_{\mathrm{B}}$ [24]. This feature makes it possible to electronically control the transconductance gain.

\subsection{The Electronically Tunable VM Biquad}

As shown in Figure 2, the capacitors $C_{1}$ and $C_{2}$ were chosen as $2.2 \mathrm{nF}$ and the bias currents were set to $\mathrm{I}_{\mathrm{B} 1}=\mathrm{I}_{\mathrm{B} 2}=\mathrm{I}_{\mathrm{B} 3}=\mathrm{I}_{\mathrm{B} 4}=200 \mu \mathrm{A}$ (that is, $\mathrm{g}_{\mathrm{m}}=2 \mathrm{mS}$ ). This setting has been designed for LPF, BPF, IBPF, IHPF, BRF, and APF responses, with $\mathrm{f}_{\mathrm{O}}=144.7 \mathrm{kHz}$ and $\mathrm{Q}=1$. Hence, the simulation and measurement functions of the $\operatorname{LPF}\left(\mathrm{V}_{\mathrm{o} 1}\right)$, IBPF $\left(\mathrm{V}_{\mathrm{o} 2}\right)$, and BRF $\left(\mathrm{V}_{\mathrm{o} 3}\right)$ in Part I are depicted in Figures 6-8, respectively. Figures 9-13 represent the simulated and measured functions of the LPF, BPF, IBPF, IHPF, and APF in Part II, respectively. The power consumption for simulation and measurement is 0.92 and $0.96 \mathrm{~W}$ under $\pm 15 \mathrm{~V}$ of supply voltage, respectively.

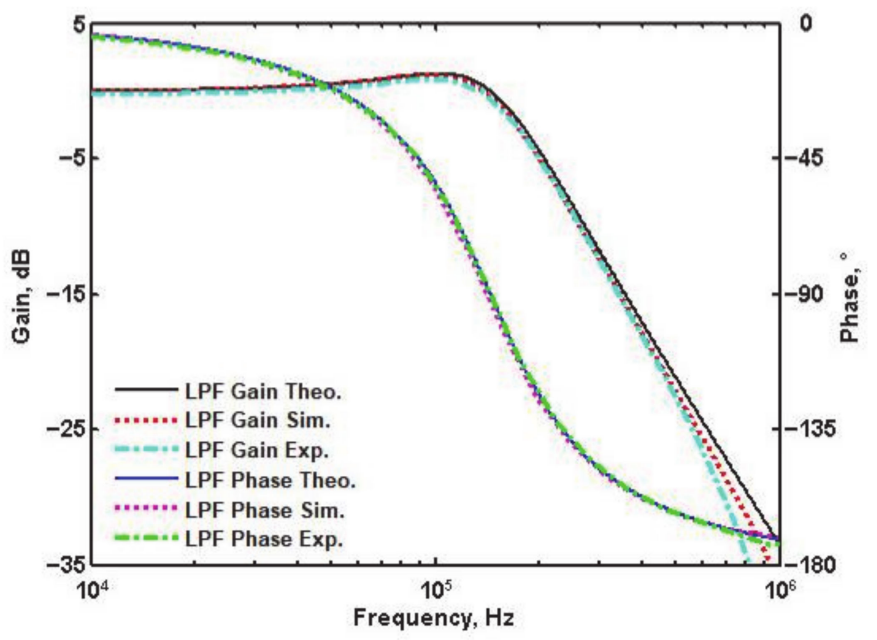

Figure 6. Comparison of LPF experimental response, simulated response, and theoretical response in Part I.

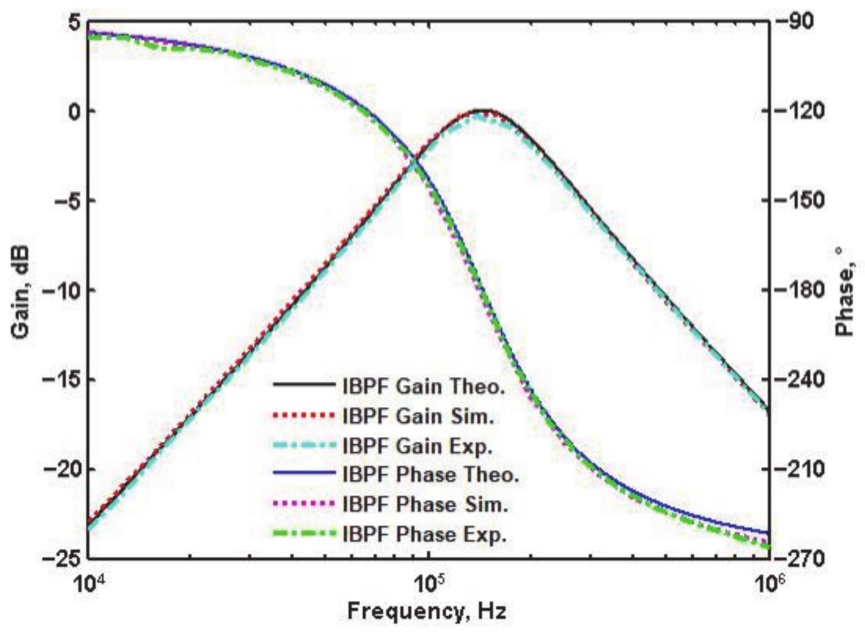

Figure 7. Comparison of IBPF experimental response, simulated response, and theoretical response in Part I. 


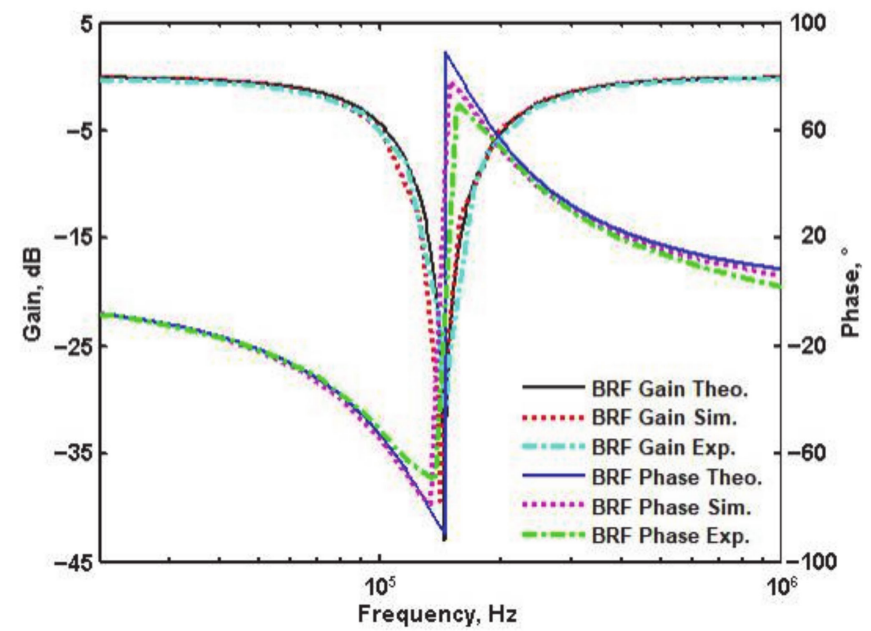

Figure 8. Comparison of BRF experimental response, simulated response, and theoretical response in Part I.

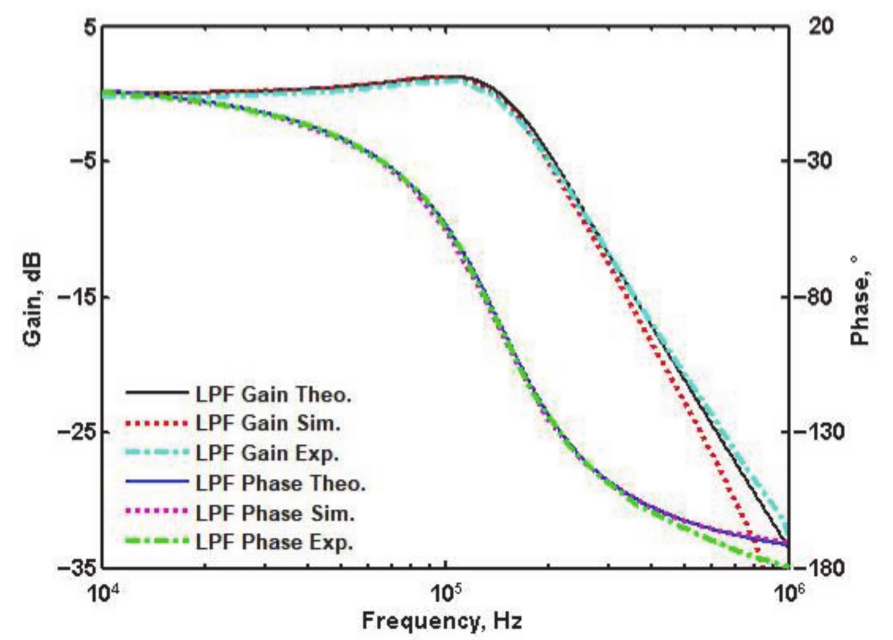

Figure 9. Comparison of LPF experimental response, simulated response, and theoretical response in Part II.

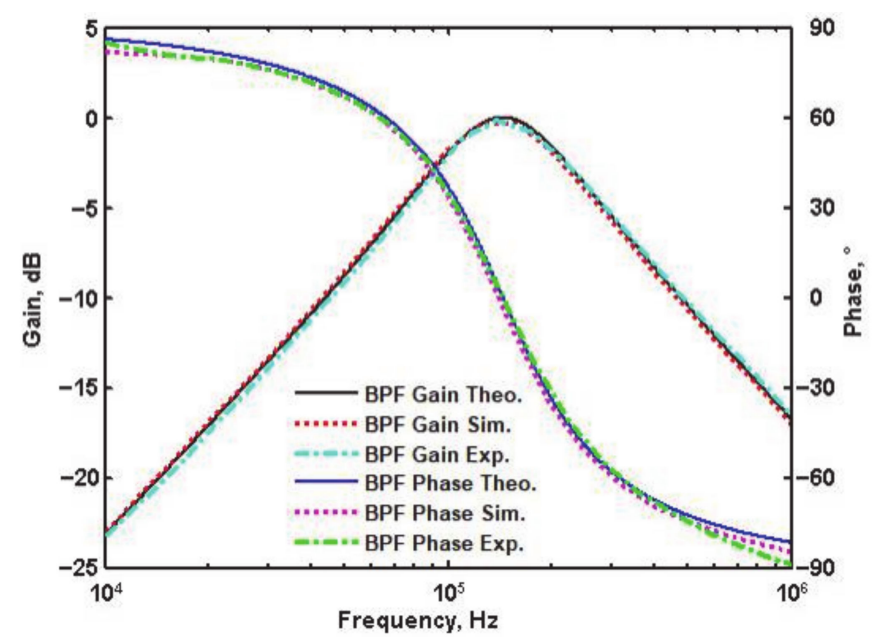

Figure 10. Comparison of BPF experimental response, simulated response, and theoretical response in Part II. 


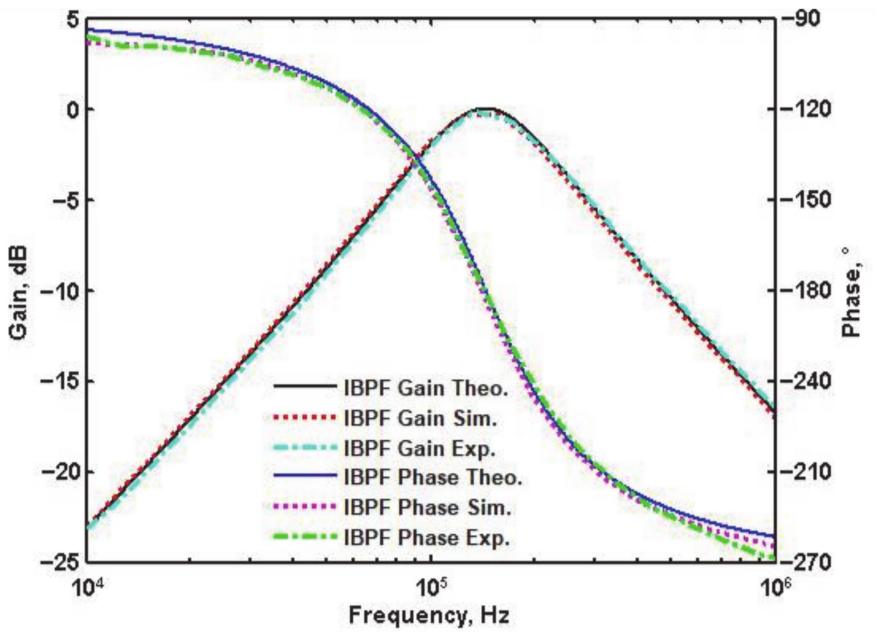

Figure 11. Comparison of IBPF experimental response, simulated response, and theoretical response in Part II.

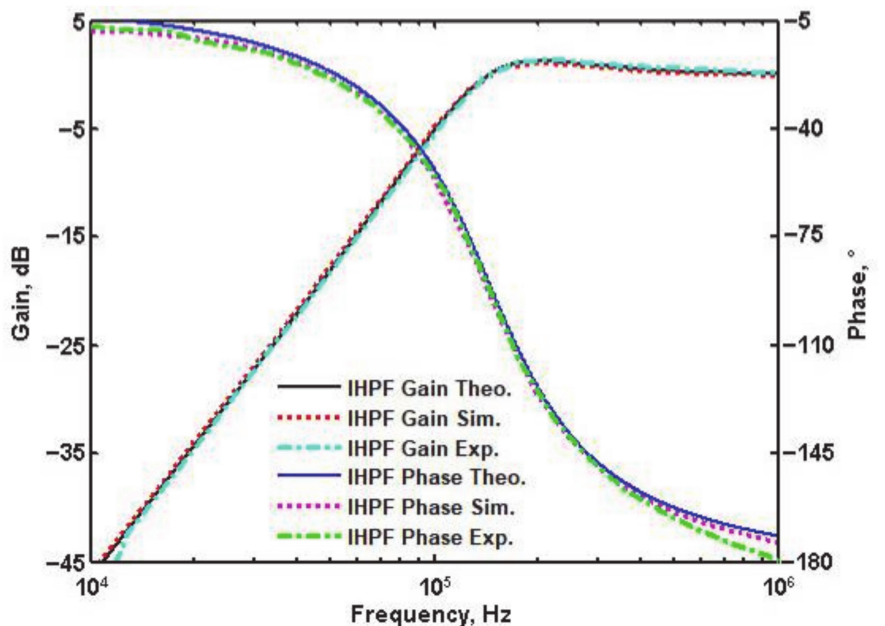

Figure 12. Comparison of IHPF experimental response, simulated response, and theoretical response in Part II.

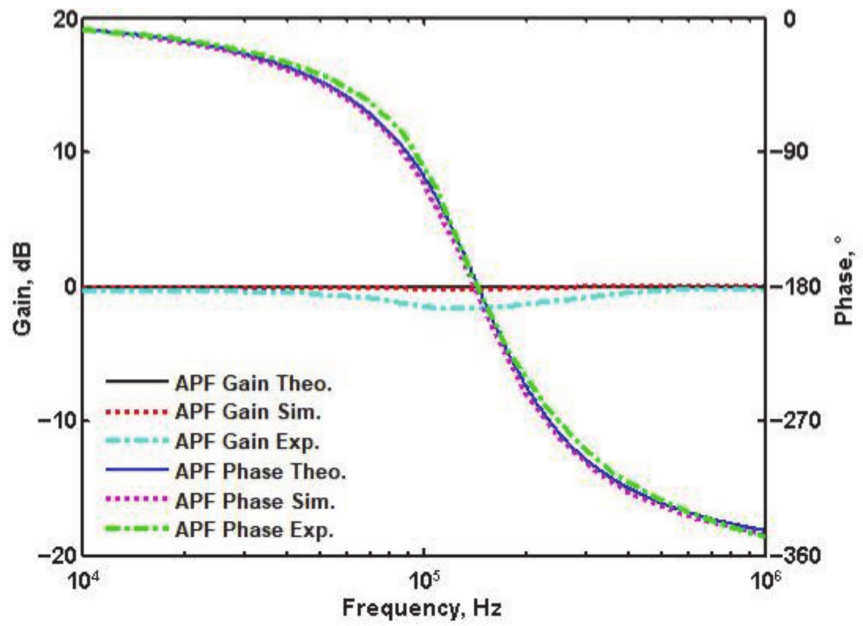

Figure 13. Comparison of APF experimental response, simulated response, and theoretical response in Part II. 
To illustrate the tunable property of natural frequency, $\mathrm{f}_{\mathrm{O}}$, without affecting the $\mathrm{Q}$, the bias currents $\mathrm{I}_{\mathrm{B} 1}=\mathrm{I}_{\mathrm{B} 2}=\mathrm{I}_{\mathrm{B} 3}$ were given as 100,200 , and $300 \mu$ A respectively, while keeping $\mathrm{C}_{1}=\mathrm{C}_{2}=2.2 \mathrm{nF}$ and $\mathrm{I}_{\mathrm{B} 4}=200 \mu \mathrm{A}$. The simulation and measurement responses of the $\mathrm{BPF}$ on the $\mathrm{V}_{\mathrm{o} 1}$ output terminal corresponding to different $\mathrm{DC}$ bias currents are shown in Figure 14, where $V_{i 3}=V_{i n}$ and $V_{i 1}=V_{i 2}=V_{i 4}=0$. As depicted in Equation (9), $Q$ can be used to adjust the transconductance gain, $g_{m 1}$, without affecting the $f_{o}$. The feature of varying the $Q$ without affecting the $f_{o}$ is shown in Figure 15. $Q$ varies $(Q=1,1.5$, and 2$)$ when $\mathrm{f}_{\mathrm{O}}$ is maintained at $144.7 \mathrm{kHz}$. In Figure 15, the $\mathrm{I}_{\mathrm{B} 1}$ was given as 200, 300, and $400 \mu \mathrm{A}$ respectively, while keeping $\mathrm{C}_{1}=\mathrm{C}_{2}=2.2 \mathrm{nF}$ and $\mathrm{I}_{\mathrm{B} 2}=\mathrm{I}_{\mathrm{B} 3}=\mathrm{I}_{\mathrm{B} 4}=200 \mu \mathrm{A}$.

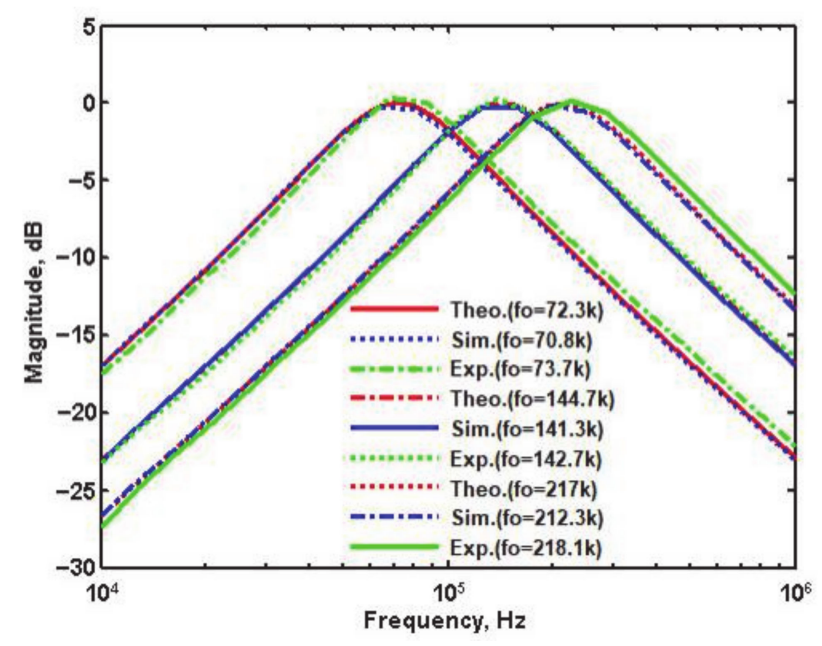

Figure 14. Gain characteristics of the BPF with different $f_{0}$.

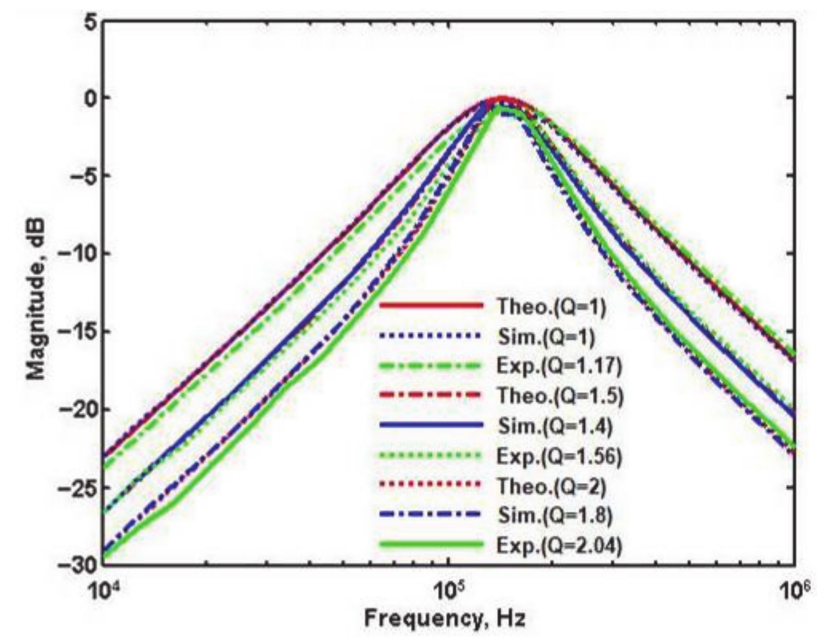

Figure 15. Gain characteristics of the BPF with different Q.

To verify the dynamic range, the proposed biquad was tested by repeating simulation of the sinusoidal input signal at $\mathrm{f}_{\mathrm{o}}=144.7 \mathrm{kHz}$. Figure 16 shows the input dynamic range of the BPF on the $V_{03}$ output terminal when only $V_{i 4}$ is applied to the input signal, which indicates an amplitude of $60 \mathrm{mV}_{\mathrm{pp}}$ (peak-to-peak) without signification distortion. The total harmonic distortion (THD) result for the BPF response is shown in Figure 17. From Figure 17, it can be obtained that the THD is about $3.92 \%$ when the input signal increases to $80 \mathrm{mV}_{\mathrm{pp}}$. Figure 18 shows the measurement of the BPF response, which can be extended to an amplitude of $60 \mathrm{mV}_{\mathrm{pp}}$ without signification distortion. Figure 19 shows the simulation output noise of the BPF versus frequency. As shown in Figure 19, the maximum output noise reaches $7.937 \mathrm{nV} / \sqrt{\mathrm{Hz}}$. Hence, the output noise was small and did not affect the proposed filter. 


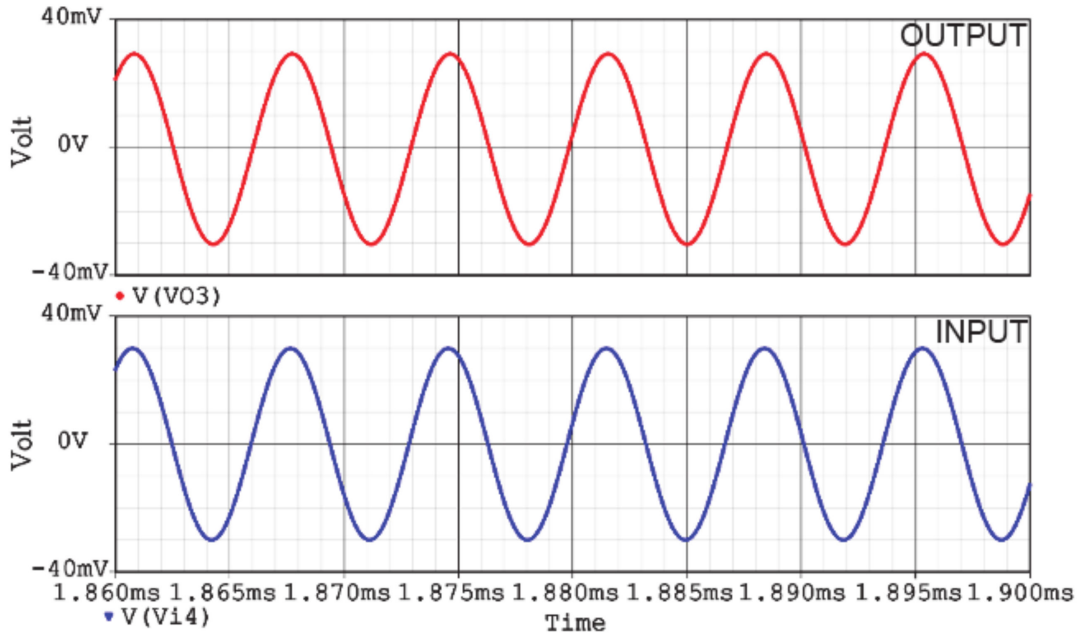

Figure 16. Time-domain BPF input and output voltage signals.

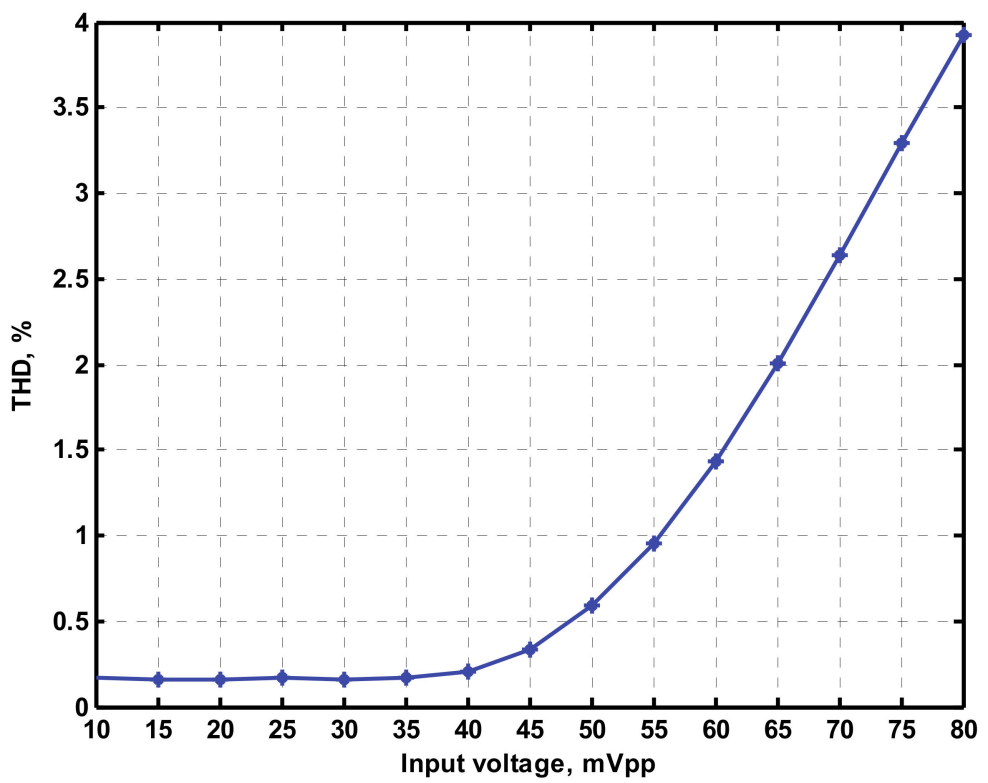

Figure 17. THD variations of the BPF against applied input voltages.

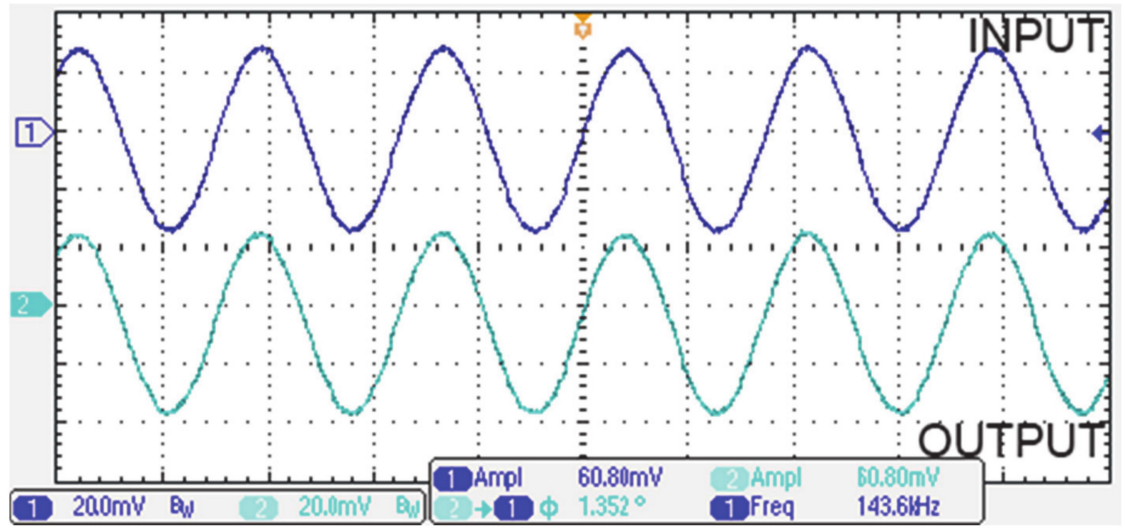

Figure 18. Time-domain BPF input and output experimental voltage signals. 


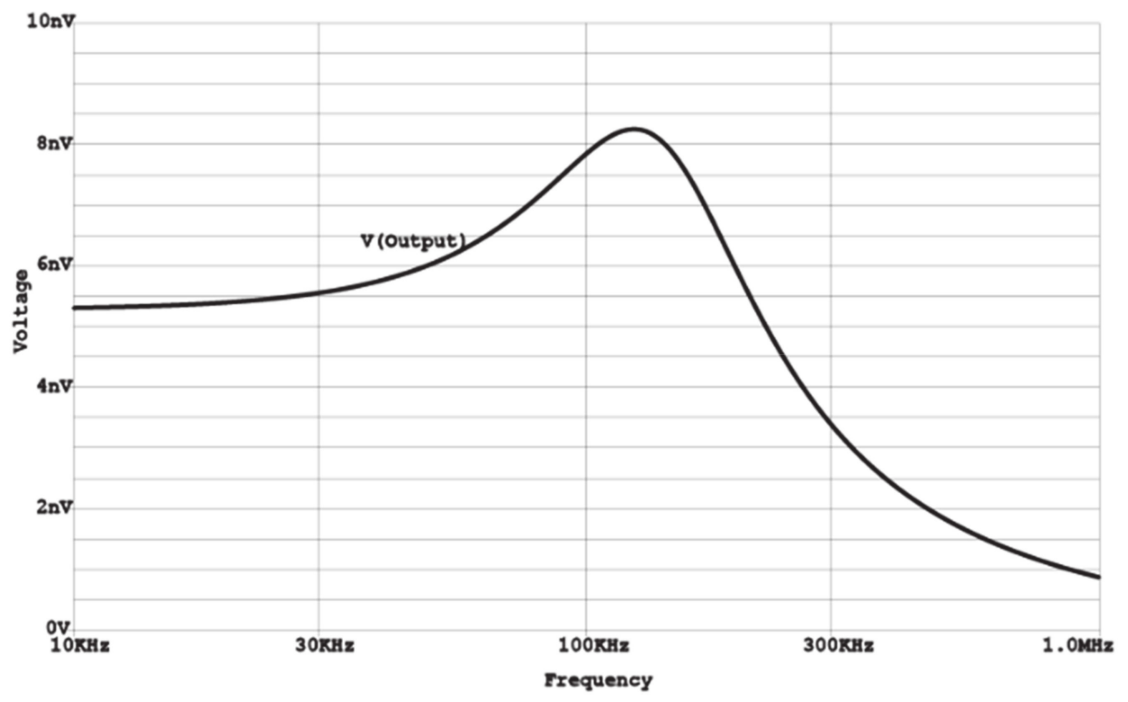

Figure 19. Noise simulation results of BPF against frequency.

To show the linearity of the biquad proposed in Figure 2, a $1 \mathrm{~dB}$ power gain compression point $(\mathrm{P} 1 \mathrm{~dB})$ of the IBPF response has been measured. Figure 20 shows the measured output P1dB of the IBPF response on the $V_{\mathrm{o} 2}$ output terminal when only $V_{\mathrm{i} 1}$ is applied to the input signal, which indicates that the measured output $\mathrm{P} 1 \mathrm{~dB}$ point is about $-7 \mathrm{dBm}$. The spectrum of the IBPF response is illustrated in Figure 21. The measured angular frequency is about $144.64 \mathrm{kHz}$, which is very close to the theoretical value of $144.69 \mathrm{kHz}$. To represent the nonlinearity of the biquad proposed in Figure 2, a two-tone testing of intermodulation distortion (IMD) has been used to characterize the nonlinearity of the IBPF response on the $V_{\mathrm{o} 2}$ output terminal. Figure 22 shows the spectrum of IBPF responses obtained by applying two-tone signals, $\mathrm{f}_{1}$ and $\mathrm{f}_{2}$, near the center frequency of $\mathrm{f}_{\mathrm{O}}=144.69 \mathrm{kHz}$ for intermodulation characterization. In Figure 22, a low-frequency tone with $\mathrm{f}_{1}=143.69 \mathrm{kHz}$ and a high-frequency tone with $\mathrm{f}_{2}=145.69 \mathrm{kHz}$ are used, and the input amplitude is equal to $126 \mathrm{mV}_{\mathrm{pp}}$. The measured value of the third-order IMD (IMD3) is about $-50.83 \mathrm{dBc}$, and the measured value of the third-order intercept (TOI) point is about $5.136 \mathrm{dBm}$. The figure-of-merit (FoM) of the biquad was defined as [14]:

$$
\text { FoM }=\frac{\text { Dynamic range } \times f_{o}}{\text { Power dissipation } \times \text { Supply voltage }}
$$

where $f_{o}$ is the central frequency. According the measured IBPF frequency spectrum in Figure 21, the dynamic range between the fundamental tone and the largest spur of the spurious-free dynamic range is approximately $53.49 \mathrm{~dB}$. Hence, the FoM of the proposed IBPF is approximately calculated as $268.75 \times 10^{3}$. 


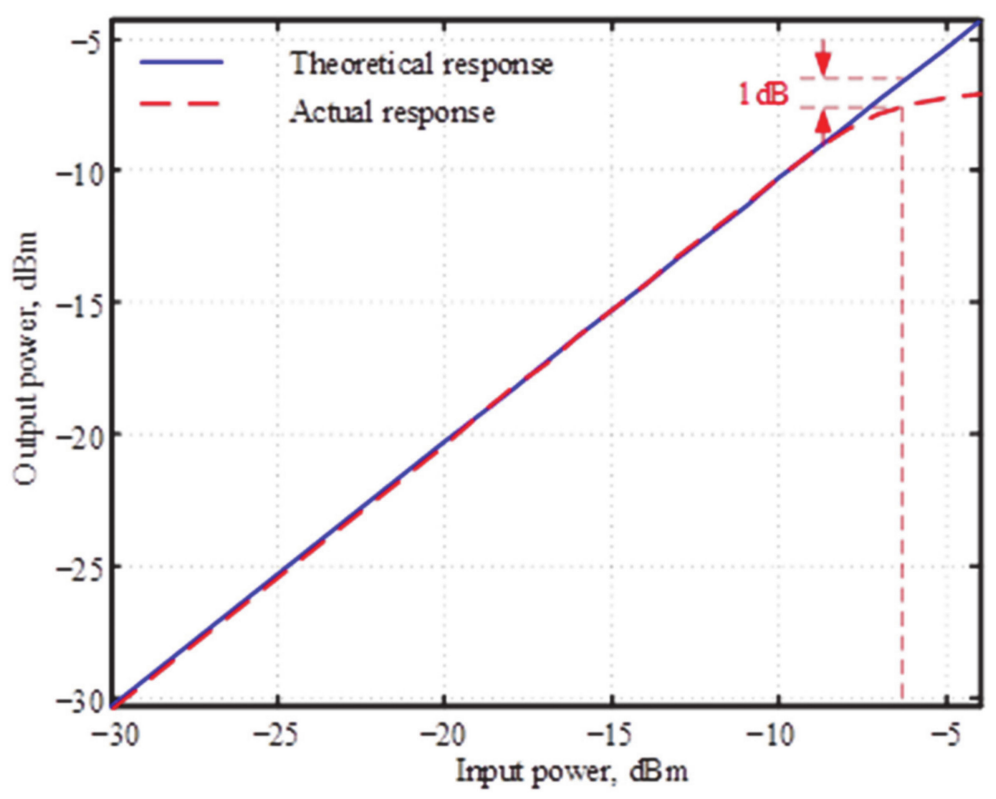

Figure 20. The measurement of $\mathrm{P} 1 \mathrm{~dB}$ at the $\mathrm{V}_{\mathrm{o} 2}$ output terminal.

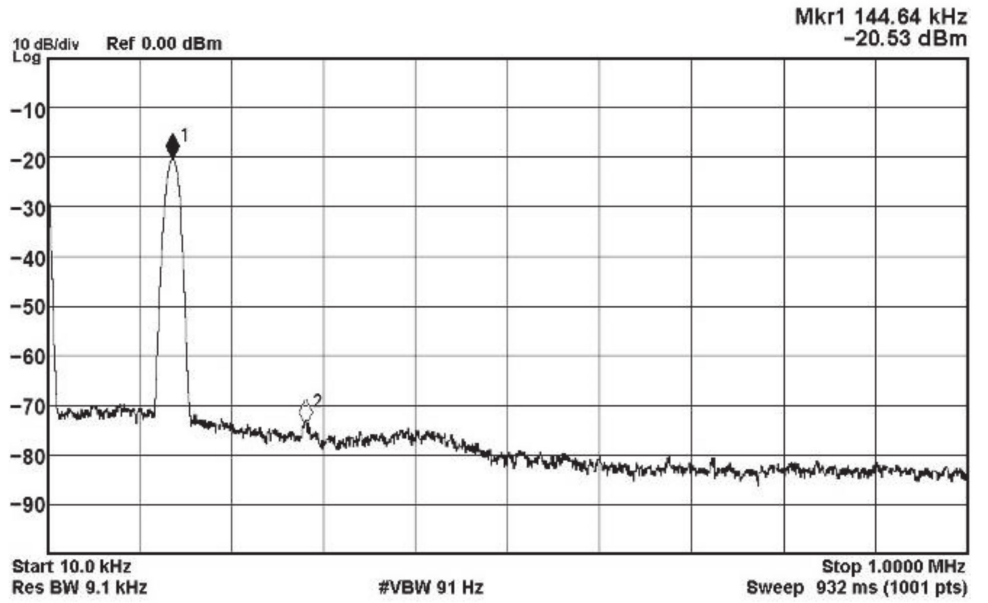

Figure 21. Frequency spectrum of the IBPF at the $\mathrm{V}_{\mathrm{o} 2}$ output terminal.

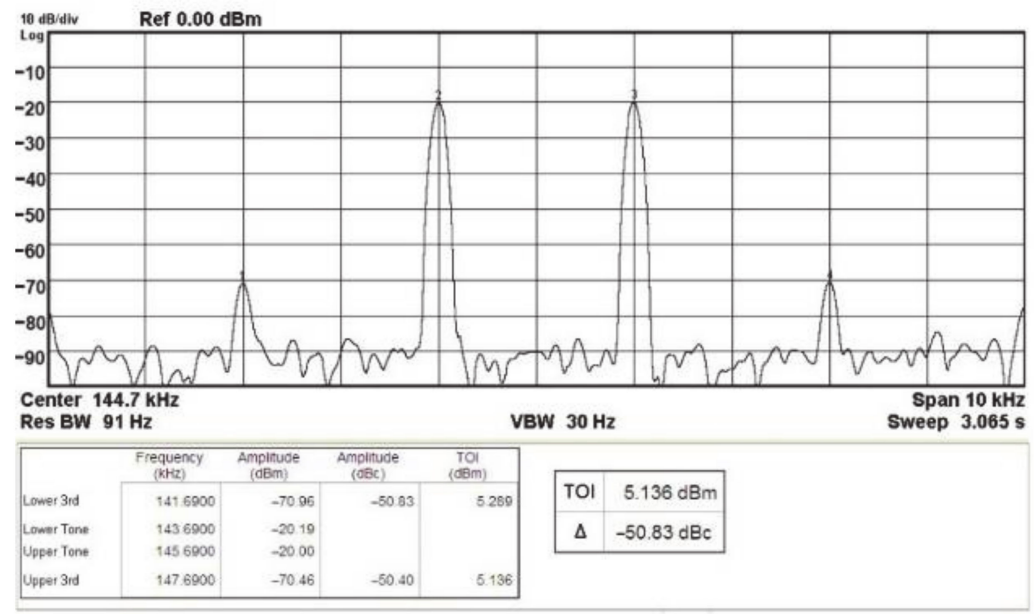

Figure 22. The IBPF output spectrum of $\mathrm{V}_{\mathrm{o} 2}$ for a two-tone -IMD test. 


\subsection{The QO with Amplitude of Output Current}

To demonstrate the theoretical study, the behavior of the proposed electronically controllable OTA-C QO with amplitude of output current has been verified by simulations and experimental measurements. The QO, as shown in Figure 3, was designed for the $\mathrm{f}_{\mathrm{o}}=72.3 \mathrm{kHz}$, with $\mathrm{g}_{\mathrm{m} 1}=1.18 \mathrm{mS}, \mathrm{g}_{\mathrm{m} 2}=\mathrm{g}_{\mathrm{m} 3}=\mathrm{g}_{\mathrm{m} 4}=1 \mathrm{mS}$, and $\mathrm{C}_{1}=\mathrm{C}_{2}=2.2 \mathrm{nF}$. As mentioned earlier, $\mathrm{g}_{\mathrm{m} 1}$ was designed to be greater than the theoretical value to guarantee start-up of oscillation. Figure 23 shows the simulation quadrature output voltage waveforms. It can be seen from the simulation results that the FO is approximately equal to $71 \mathrm{kHz}$, close to the theoretical value, and the error rate is $-1.8 \%$. Figure 24 represents the experimental quadrature outputs $\mathrm{V}_{\mathrm{O} 1}$ and $\mathrm{V}_{\mathrm{O} 3}$. According to the experimental results, the measured FO is equal to $73.78 \mathrm{kHz}$, which is close to the theoretical value, and the error rate is $2 \%$. Figure 25 shows the simulated and experimental results of the FO by varying the values of $g_{\mathrm{m} 3}$. Figure 26 shows how to calculate the phase noise using the Agilent phase noise measurement solution. The phase noise in the proposed electronically controllable OTA-C QO is lower than $-74.93 \mathrm{dBc} / \mathrm{Hz}$ (at $1 \mathrm{kHz}$ offset). To show the usability of the electronically controllable OTA-C QO in Figure 3, the applications of AM and ASK generators are confirmed in Figures 27-32, where $\mathrm{I}_{B 4}$ is sine wave, triangle wave, and pulse signals respectively, with a frequency of $7.4 \mathrm{kHz}$. These simulation and experimental measurements are close to the theoretical prediction, confirming the feasibility of the proposed electronically controllable OTA-C QO.

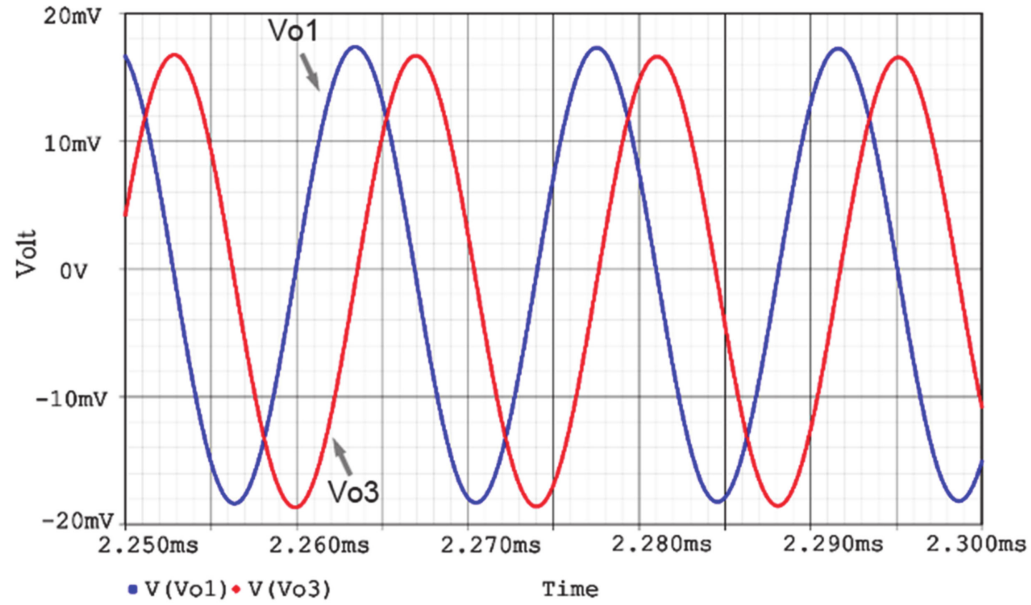

Figure 23. The steady-state simulation waveform of the quadrature voltage outputs.

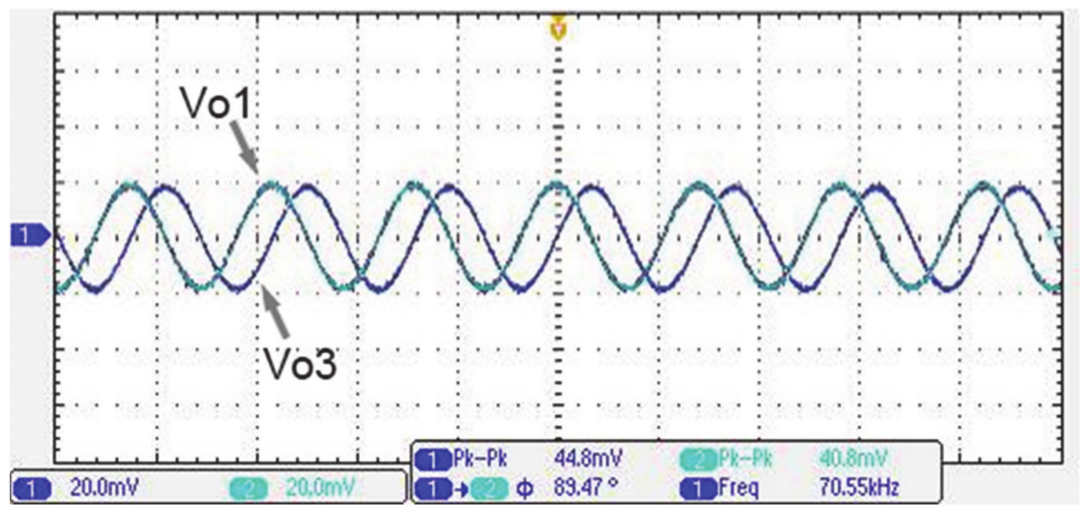

Figure 24. Measured result of quadrature voltage waveforms. 


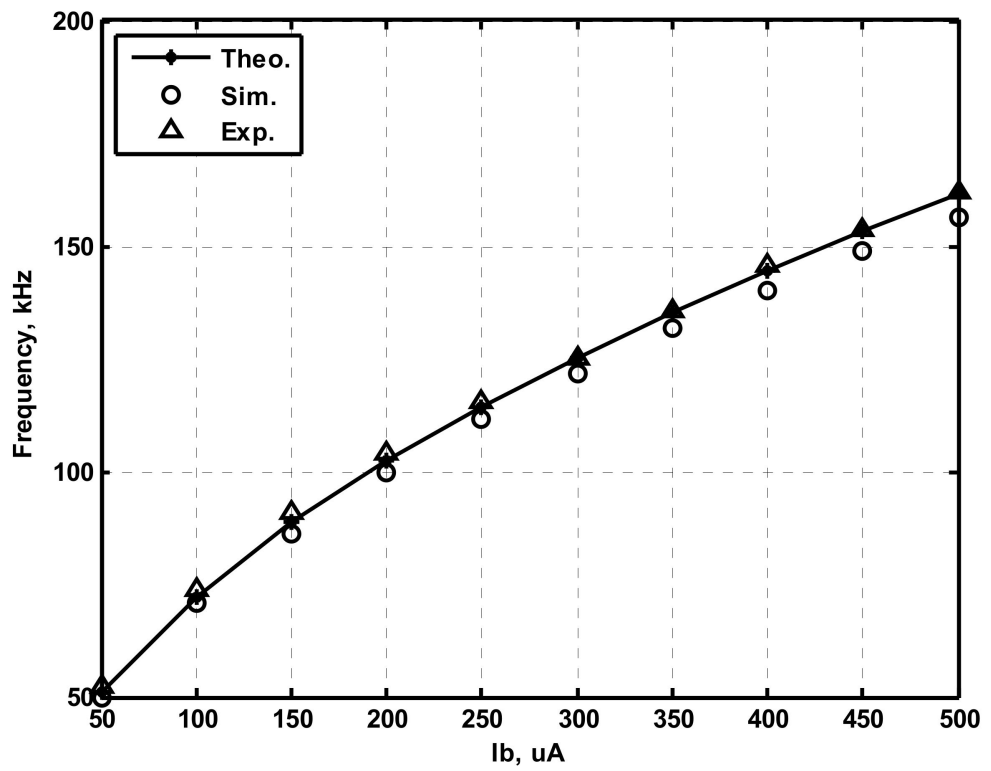

Figure 25. Results of the FO by varying $\mathrm{g}_{\mathrm{m} 3}$.

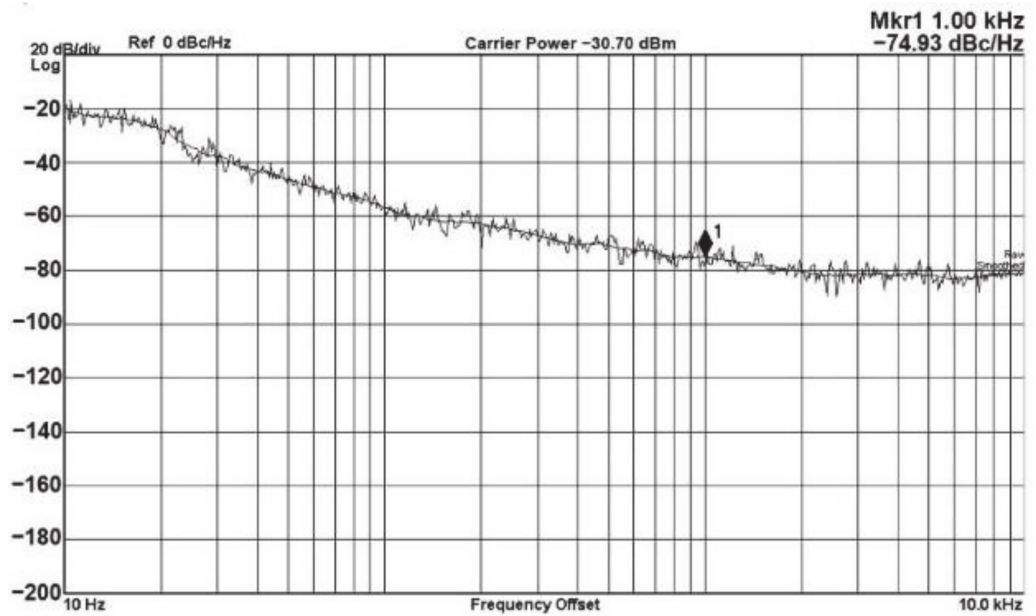

Figure 26. Measured result of the phase noise.

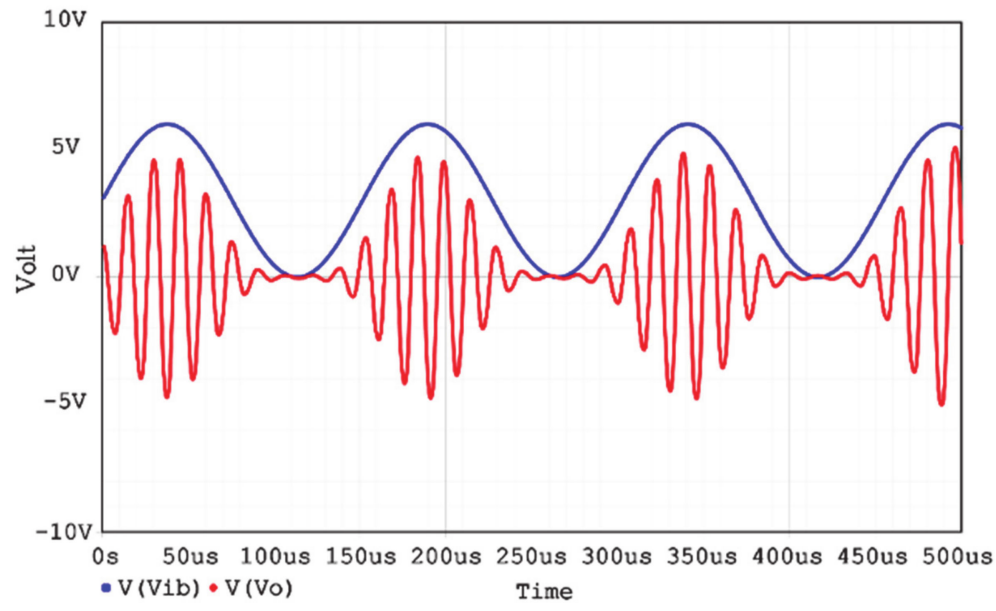

Figure 27. The simulation result of the AM signal generator using sine wave input signal. 


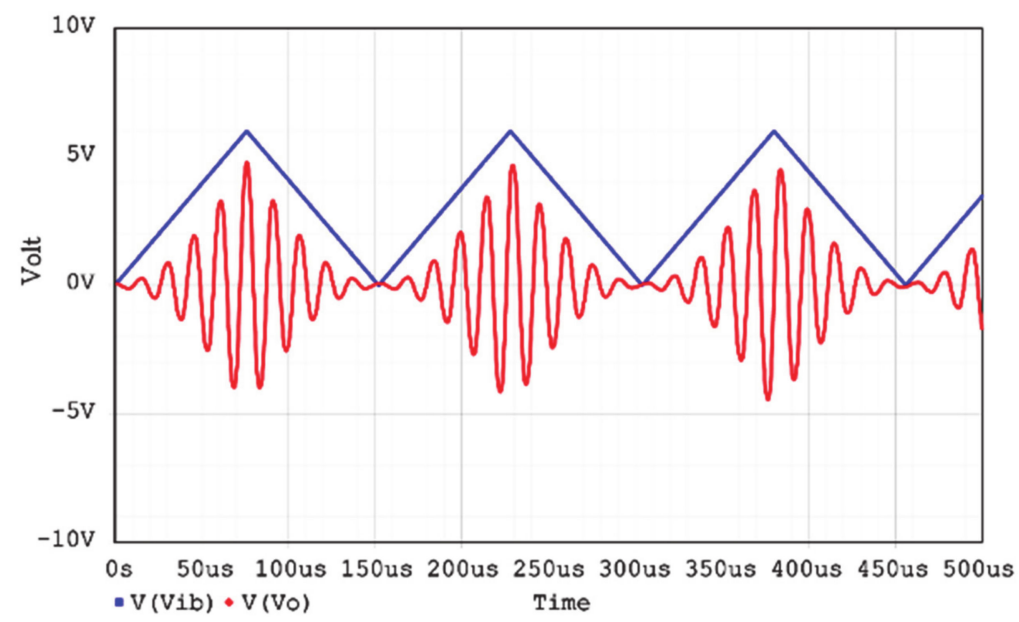

Figure 28. The simulation result of the AM signal generator using triangle wave input signal.

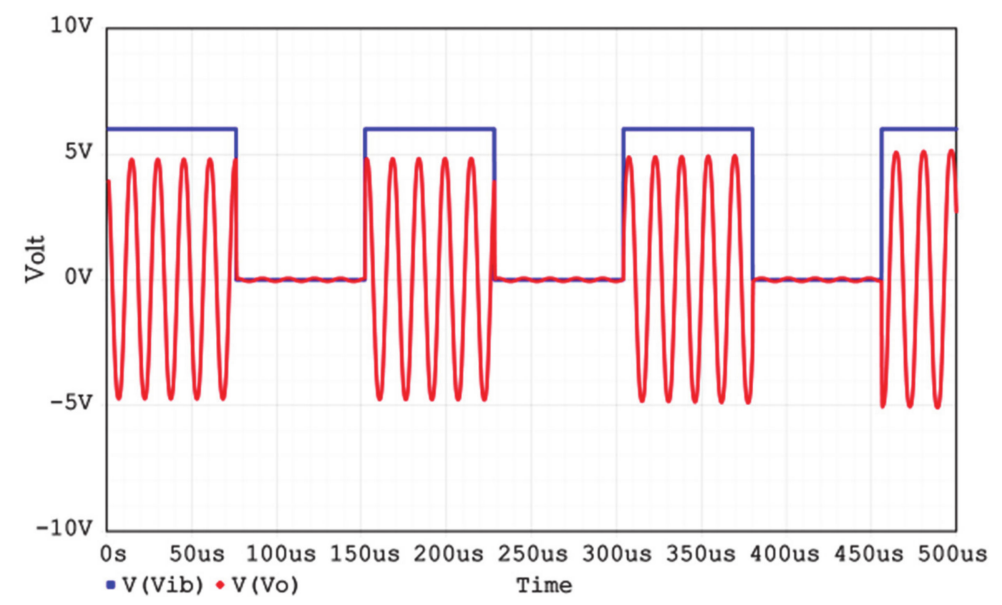

Figure 29. The simulation result of the ASK signal generator using pulse wave input signal.

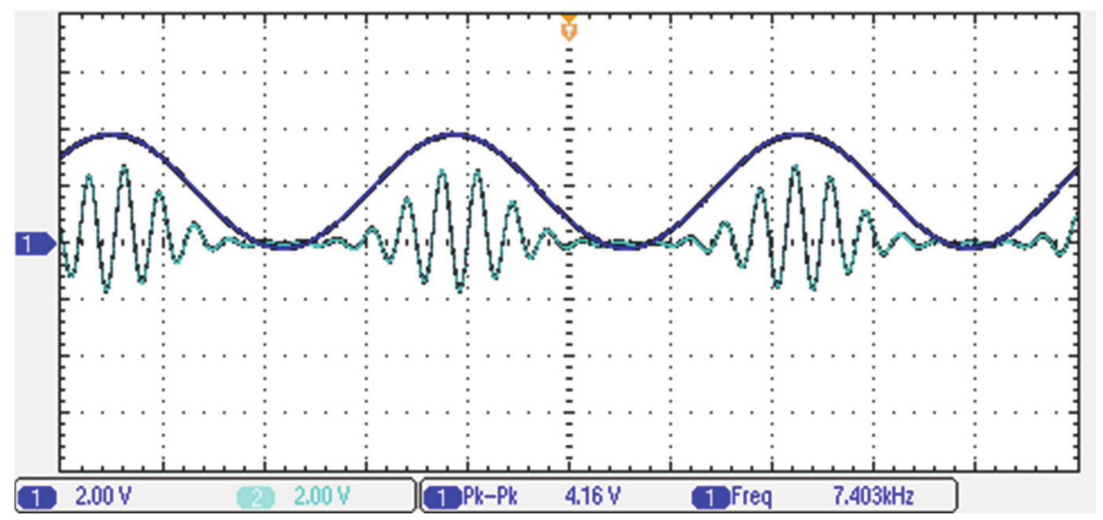

Figure 30. The measurement result of the AM signal generator using sine wave input signal. 


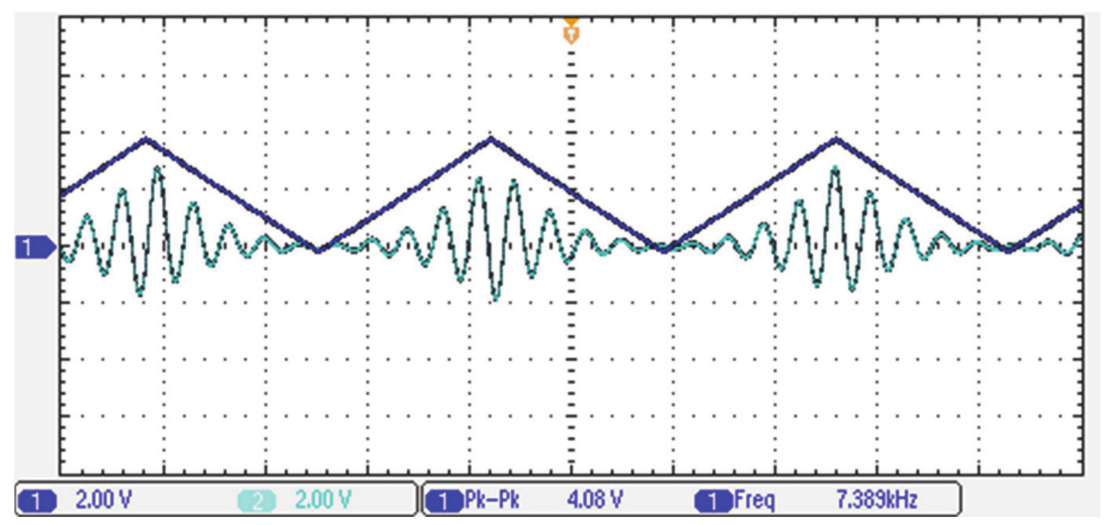

Figure 31. The measurement result of the AM signal generator using triangle wave input signal.

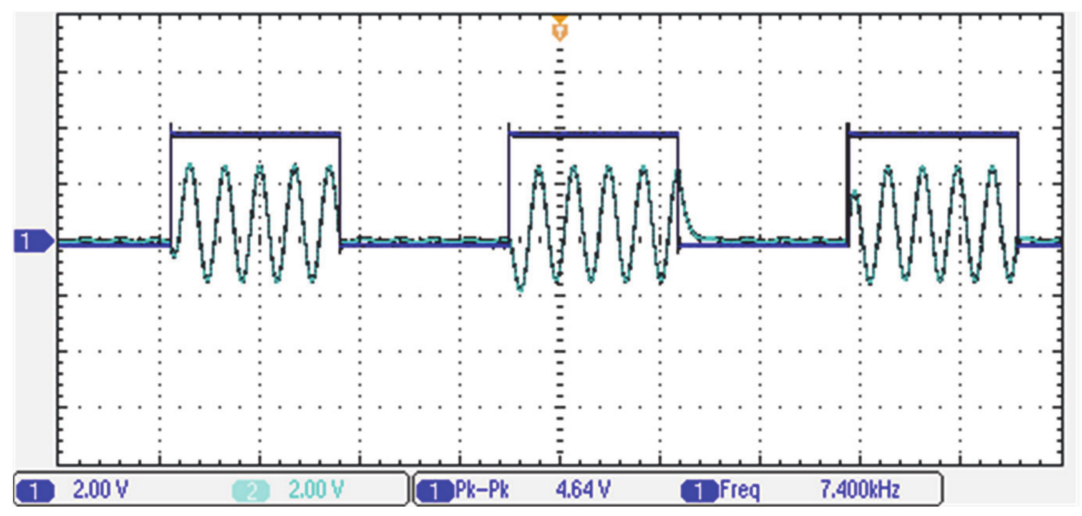

Figure 32. The measurement result of the ASK signal generator using pulse wave input signal.

\section{Conclusions}

This paper presented an electronically tunable biquad and an output current amplitude, electronically tunable QO. The proposed circuits employed three OTAs, one DO-OTA, and two grounded capacitors. The single-input three-output VM multifunction biquad or the four-input single-output VM universal biquad can work in the same configuration. The proposed biquad can simultaneously realize LPF, IBPF, and BRF responses. By choosing the appropriate input terminals, the proposed biquad can realize all standard filtering functions without inverting-type voltage input signals. The characteristic parameters $\omega_{\mathrm{o}}$ and $\mathrm{Q}$ are orthogonally controllable. The measured value of the power dissipation was $0.96 \mathrm{~W}$, under $32 \mathrm{~mA}$ constant output current. The measured P1dB value of the output IBPF was $-7 \mathrm{dBm}$, and the measured IMD3 and TOI values were $-50.83 \mathrm{dBc}$ and $5.136 \mathrm{dBm}$, respectively. The measured value of the spurious-free dynamic range was $53.49 \mathrm{~dB}$, and the FoM of the filter was $268.75 \times 10^{3}$. The proposed biquad configuration can be used as a type of electronically tunable $\mathrm{QO}$ with high-output impedance and amplitude-controllable sinusoidal current output signal. The proposed electronically tunable QO generated two sinusoidal output voltages with $90^{\circ}$ phase difference, and $\mathrm{CO}$ and $\mathrm{FO}$ can be adjusted independently by adjusting the $\mathrm{I}_{\mathrm{B}}$ of the OTA. Moreover, the proposed QO with electronically controllable amplitude of the sinusoidal current output signal can provide an AM signal or ASK signal, and is widely utilized in modulation systems. The proposed circuits have been verified by experiments and verified by OrCAD PSpice simulations to confirm the theoretical and expected assumptions.

Author Contributions: S.-F.W. and H.-P.C. conceived and designed the theoretical verifications; Y.K. revised the manuscript to improve the quality of English; H.-P.C. analyzed the results and wrote the paper; F.-Y.L. performed the simulations and experiments. All authors have read and agreed to the published version of the manuscript. 
Funding: This research received no external funding.

Institutional Review Board Statement: Not applicable.

Informed Consent Statement: Not applicable.

Data Availability Statement: Not applicable.

Conflicts of Interest: The authors declare no conflict of interest.

\section{References}

1. Arora, T.S.; Gupta, S. A new voltage mode quadrature oscillator using grounded capacitors: An application of CDBA. Eng. Sci. Technol. 2018, 21, 43-49. [CrossRef]

2. Bhaskar, D.R.; Gupta, S.S.; Senani, R. New CFOA-based sinusoidal oscillators retaining independent control of oscillation frequency even under the influence of parasitic impedances. Analog Integr. Circuits Signal Process. 2012, 73, 427-437. [CrossRef]

3. Bhaskar, D.R.; Senani, R. New CFOA-based single-element-controlled sinusoidal oscillators. IEEE Trans. Instrum. Meas. 2006, 55, 2014-2021. [CrossRef]

4. Senani, R.; Singh, V.K. Novel single-resistance-controlled-oscillator configuration using current-feedback-amplifiers. IEEE Trans. Circuits Syst. I Fundam. Theory Appl. 1996, 43, 698-700. [CrossRef]

5. Abuelma'atti, M.T.; Farooqi, A.A.; Alshahrani, S.M. Novel RC oscillators using the current-feedback operational amplifier. IEEE Trans. Circuits Syst. I Fundam. Theory Appl. 1996, 43, 155-157. [CrossRef]

6. Jaikla, W.; Adhan, S.; Suwanjan, P.; Kumngern, M. Current/voltage controlled quadrature sinusoidal oscillators for phase sensitive detection using commercially available IC. Sensors 2020, 20, 1319. [CrossRef] [PubMed]

7. Kumari, S.; Gupta, S.; Pandey, N.; Pandey, R.; Anurag, R. LC-ladder filter systematic implementation by OTRA. Eng. Sci. Technol. 2016, 19, 1808-1814. [CrossRef]

8. Verma, R.; Pandey, N.; Pandey, R. CFOA based low pass and high pass fractional step filter realizations. AEU Int. J. Electron. Commun. 2019, 99, 161-176. [CrossRef]

9. Liao, P.H.; Hwang, Y.S.; Chen, J.J.; Ku, Y.; Wang, S.F. A new low-voltage operational transconductance amplifier with push-pull CMFB scheme for low-pass filter applications. AEU Int. J. Electron. Commun. 2020, 123, 153298. [CrossRef]

10. Tangsrirat, W.; Channumsin, O. High-input impedance voltage-mode multifunction filter using a single DDCCTA and grounded passive elements. Radioengineering 2011, 20, 905-910.

11. Yuce, E.; Verma, R.; Pandey, N.; Minaei, S. New CFOA-based first-order all-pass filters and their applications. AEU Int. J. Electron. Commun. 2019, 103, 57-63. [CrossRef]

12. Minaei, S.; Yuce, E. All-grounded passive elements voltage-mode DVCC-based universal filters. Circuits Syst. Signal. Process. 2010, 29, 295-309. [CrossRef]

13. Yuce, E.; Tez, S. A novel voltage-mode universal filter composed of two terminal active devices. AEU Int. J. Electron. Commun. 2018, 86, 202-209. [CrossRef]

14. Alpaslan, H.; Yuce, E. DVCC+ based multifunction and universal filters with the high input impedance features. Analog Integr. Circuits Signal. Process. 2020, 103, 325-335. [CrossRef]

15. Acosta, L.; Jimenez, M.; Carvajal, R.G.; Lopez-Martin, A.J.; Ramirez-Angulo, J. Highly linear tunable CMOS gm-C low-pass filter. IEEE Trans. Circuits Syst. I Regul. Pap. 2009, 56, 2145-2158. [CrossRef]

16. Tao, Y.; Fidler, J.K. Electronically tunable dual-OTA second-order sinusoidal oscillators / filters with non-interacting controls: A systematic synthesis approach. IEEE Trans. Circuits Syst. I Fundam. Theory Appl. 2000, 47, 117-129.

17. Tu, S.H.; Hwang, Y.S.; Chen, J.J.; Soliman, A.M.; Chang, C.M. OTA-C arbitrary-phase-shift oscillators. IEEE Trans. Instrum. Meas. 2012, 61, 2305-2319. [CrossRef]

18. Kumar, K.; Pal, K. Voltage mode multifunction OTA-C biquad filter. Microelectron. Int. 2006, 23, 24-27. [CrossRef]

19. Kumar, K.; Pal, K.; Gupta, G.K. Realization of multi-function biquad filter using operational transconductance amplifier. Indian J. Pure Appl. Phy. 2006, 44, 71-74.

20. Kumngern, M.; Suwanjan, P.; Dejhan, K. Electronically tunable voltage-mode universal filter with single-input five-output using simple OTAs. Int. J. Electron. 2013, 100, 1118-1133. [CrossRef]

21. Bhaskar, D.R.; Raj, A.; Kumar, P. Mixed-mode universal biquad filter using OTAs. J. Circuits, Syst. Comput. 2020, $29,2050162$. [CrossRef]

22. Senani, R. New OTA-C universal current-mode/trans-admittance biquads. IEICE Electron. Exp. 2005, 2, 8-13.

23. Lee, C.N. High-order multiple-mode and trans-admittance mode OTA-C universal filters. J. Circuits Syst. Comput. 2012, 21, 1520048. [CrossRef]

24. LT1228-100 MHz Current Feedback Amplifier with DC Gain Control. Linear Technology Corporation Version Number D. 2012. Available online: http:/ / www.linear.com/product/LT1228 (accessed on 1 October 2019).

25. Psychalinos, C.; Kasimis, C.; Khateb, F. Multiple-input single-output universal biquad filter using single output operational transconductance amplifiers. AEU Int. J. Electron. Commun. 2018, 93, 360-367. [CrossRef]

26. Kumngern, M.; Suksaibul, P.; Khateb, F. Four-input one-output voltage-mode universal filter using simple OTAs. J. Circuits Sys. Comp. 2019, 28, 1950078. [CrossRef] 
27. Wang, S.F.; Chen, H.P.; Ku, Y.; Yang, C.M. A voltage-mode universal filter using five single-ended OTAs with two grounded capacitors and a quadrature oscillator using the voltage-mode universal filter. Opt. Int. J. Light Electron. Opt. 2019, 192, 162950. [CrossRef]

28. Wang, S.F.; Chen, H.P.; Ku, Y.; Lin, Y.C. Versatile tunable voltage-mode biquadratic filter and its application in quadrature oscillator. Sensors 2019, 19, 2349. [CrossRef] [PubMed]

29. Wang, S.F.; Chen, H.P.; Ku, Y.; Yang, C.M. Independently tunable voltage-mode OTA-C biquadratic filter with five inputs and three outputs and its fully-uncoupled quadrature sinusoidal oscillator application. AEU Int. J. Electron. Commun. 2019, 100, 152822. [CrossRef]

30. Wang, S.F.; Chen, H.P.; Ku, Y.; Lee, C.L. Versatile voltage-mode biquadratic filter and quadrature oscillator using four OTAs and two grounded capacitors. Electronics 2020, 9, 1493. [CrossRef] 